University of Rhode Island

DigitalCommons@URI

Open Access Master's Theses

1982

\title{
A Hydrogen Permeation Study of Electroplated Cadium on an Iron Substrate
}

Ben G. Allen

University of Rhode Island

Follow this and additional works at: https://digitalcommons.uri.edu/theses

\section{Recommended Citation}

Allen, Ben G., "A Hydrogen Permeation Study of Electroplated Cadium on an Iron Substrate" (1982). Open Access Master's Theses. Paper 1098.

https://digitalcommons.uri.edu/theses/1098

This Thesis is brought to you for free and open access by DigitalCommons@URI. It has been accepted for inclusion in Open Access Master's Theses by an authorized administrator of DigitalCommons@URI. For more information, please contact digitalcommons-group@uri.edu. 
A HYDROGEN PERMEATION STUDY OF ELECTROPLATED CADMIUM ON AN IRON SUBSTRATE BY

BEN G. ALLEN

A THESIS SUBMITTED IN PARTIAL FULFILLMENT OF THE REQUIREMENTS FOR THE DEGREE OF

MASTERS OF SCIENCE

IN

OCEAN ENGINEERING 


\title{
MASTER OF SCIENCE THESIS
}

\author{
OF
}

BEN G. ALLEN

Approved:

Thesis Committee

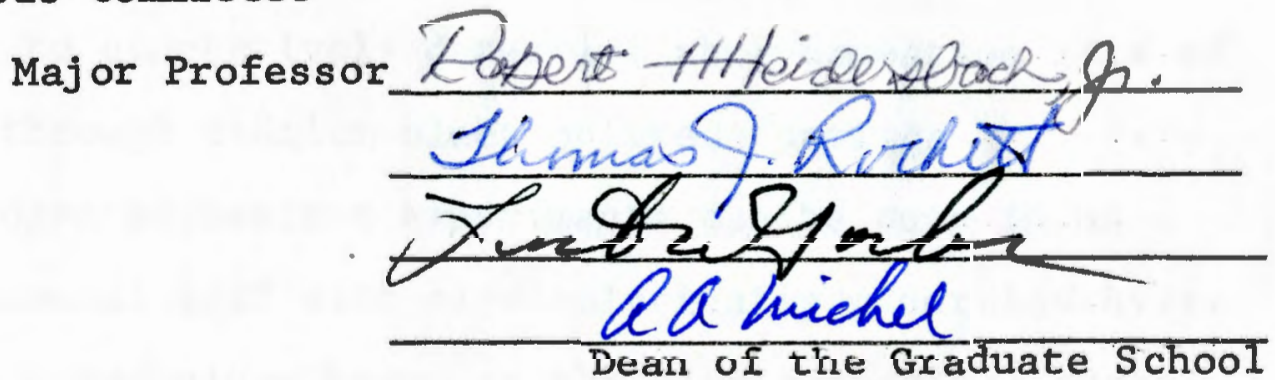

UNIVERSITY OF RHODE ISLAND

1982 


\section{ABSTRACT}

Electroplated cadmium is currently used as an effective hydrogen diffusion barrier on ferrous based alloys. Many of these alloys are susceptable to hydrogen embrittlement, and cadmium electroplating has been shown to be a very efficient method of reducing hydrogen induced failures. However, industrial cadmium plating wastes are toxic and expensive to process for proper disposal. Current government regulations regarding this waste disposal have encouraged commercial platers away from cadmium as an amphoteric coating. Zinc is frequently used and aluminum looks encouraging as an alternative to cadmium electroplates. In order to accurately assess the effectiveness of these alternative coatings to cadmium, it is first necessary to quantatively determine the permeation rate of hydrogen through cadmium electroplated coatings.

Hydrogen permeation experiments can be done in an electrochemical cell with electrolytically generated hydrogen using a technique known as the electrochemical hydrogen permeation method. Previous work at the University of Rhode Island, using this method, has determined the necessity for a controlled sample preparation technique in order to get reproducibility of data. It has also been determined that it is necessary to coat the inlet and exit surfaces of the sample membrane with an inert coating to 
prevent reaction of the test sample material or coating with either the inlet or exit electrolyte. Also, this inert coating must not be the rate determining step for the hydrogen permeation rate. In this project, an electroplating bath and technique was developed that would provide a thin flash of palladium over the inlet and exit surfaces of the sample membrane. Electron microscopy was used to check the integrity of these inert coatings.

The base metal chosen for this project was a high purity "Ferrovac E" iron. The first phase of the tests was to replicate earlier experiments on a pure palladium-ironpalladium membrane in order to confirm the proper functioning of the experimental technique.

After this, it was necessary to determine the rate controlling step of the sample membrane with a cadmium electroplate just inside the palladium coating on the inlet side of the membrane. Cadmium should be rate controlling, and this is determined by varying the thickness of the iron substrate and observing the variations in steady state permeation rates.

Finally, the effects of various thicknesses of cadmium electroplated coatings was determined by observing the changes in steady state permeation rates.

The results of tests with samples without cadmium coating closely resembled those of earlier researchers at University of Rhode Island, which confirmed the proper 
function of the equipment. The tests performed with a constant cadmium plating thickness and various Iron substrate thicknesses showed a relatively small difference in steady state permeation rate, which proved the cadmium layer to be the rate controlling step. The tests with various thicknesses of cadmium on a constant iron substrate thickness proved again that the cadmium was rate controlling. 


\section{Acknowledgment}

This thesis is dedicated to my family and Dr. Robert H. Heidersbach, for it was through their support and guidance that this thesis was completed. 
$\underline{\text { Page }}$

Abstract

ii

Acknowledgement

vi

List of Tables

List of Figures

vii

viii

Chapter 1 INTRODUCTION
A. Statement of The Problem
1
B. Prior Work on Project
11
C. Purpose

Chapter 2 EXPERIMENTAL
A. Plating Development
21
B. Hydrogen Permeation System
27
C. Experimental Plan

Chapter 3 RESULTS
A. Plating Development
B. Tests With Iron Substrate
39
C. Effects of Anodic Coatings

Chapter 4 DISCUSSIONS \& CONCLUSIONS
A. Plating Comments
B. Iron Samples
C. Cadmium Effects

Chapter 5 RECOMMENDATIONS FOR FUTURE WORK

$\begin{array}{ll}\text { A. Plating Suggestions } & 55 \\ \text { B. Alternative Coatings } & 55\end{array}$

REFERENCES 58

APPENDICES 62

BIBLIOGRAPHY 85 


\section{LIST OF TABLES}

\section{Page}

Table I Hydrogen permeation rate summary

14 through iron

Table II Sample preparation technique

15

Table III Cadmium bath composition

24

Table IV Ferrovac "E" composition

28

Table V Sample cleaning and plating schedules

31

Table VI Sample exposure plan

37

Table VII Interstitial hole sizes for

57 various metals 


\section{List of Figures}

$\underline{\text { Page }}$

Figure 1 The characteristic diagram of load versus

2 time for hydrogen induced failure

Figure 2 Pourbaix diagram for iron

Figure 3 Pourbaix diagram for palladium

Figure 4 Typed sample membrane

Figure 5 The Hull Cell

Figure 6 The electroplating system

Figure 7 The hydrogen permeation cell

Figure 8 The electrochemical hydrogen permeation system

Figure 9 Flux trainsients without cadmium at $1.0 \mathrm{ma}$ charging rate.

Figure 10 Flux trainsients without cadmium at $0.5 \mathrm{ma}$ charging rate.

Figure 11 Flux trainsients with $0.2 \mathrm{mils}$ cadmium on $20 \mathrm{mils}$ iron at $0.5 \mathrm{ma}$ charging rate.

Figure 12 Flux trainsients with $0.2 \mathrm{mils}$ cadmium on $40 \mathrm{mils}$ iron at $0.5 \mathrm{ma}$ charging rate.

Figure 13 Flux transients with 0.2 mils cadmium on 80 mils iron at 0.5 ma charging rate.

Figure 14 Flux trainsients with $0.2 \mathrm{mils}$ cadmium on 22.5 mils iron at $0.5 \mathrm{ma}$ charging rate.

Figure 15 Flux trainsients with $0.5 \mathrm{mils}$ cadmium on 25 mils iron at $0.5 \mathrm{ma}$ charging rate.

Figure 16 Composite of all flux transients with 0.2 mils cadmium at 0.5 ma charging rate.

Figure 17 Inverse thickness versus steady state flux for cadmium coated samples.

Figure 18 Steady-state hydrogen concentration through 54 cadmium plated sample. 
CHAPTER 1

INTRODUCTION

\section{A. Statement of the Problem}

The detrimental effects of hydrogen on metals was first documented by Deville and Troost in 1853 (1). Since that time much research and several conferences have been specially devoted to hydrogen in metals (2-5). In 1941, Zapffe and Sims (6) referenced 104 papers on this subject and documented then the debates over proposed mechanisms of failure, many of which now have been discarded. To illustrate the mechanical effects of hydrogen embrittlement, Figure 1 represents the nature of a metals response to hydrogen and shows the delayed fracture typical for a hydrogen induced failure.

Several proposed mechanisms of hydrogen embrittlement over the years have been updated to more inclusive theories (7). Loutham and McNitt (8) presented a comprehensive review of modern mechanisms, and Latanison, et. al. (9) assigned the labels to the summaries presented below.

Pressure Model. This mechanism was originally proposed by Zapffe (10) in 1941 and subsequently modified by others from 1954 to 1974. The pressure developed by the conversion of atomic hydrogen to molecular hydrogen at internal defects lowers the external stress required for fracture. 


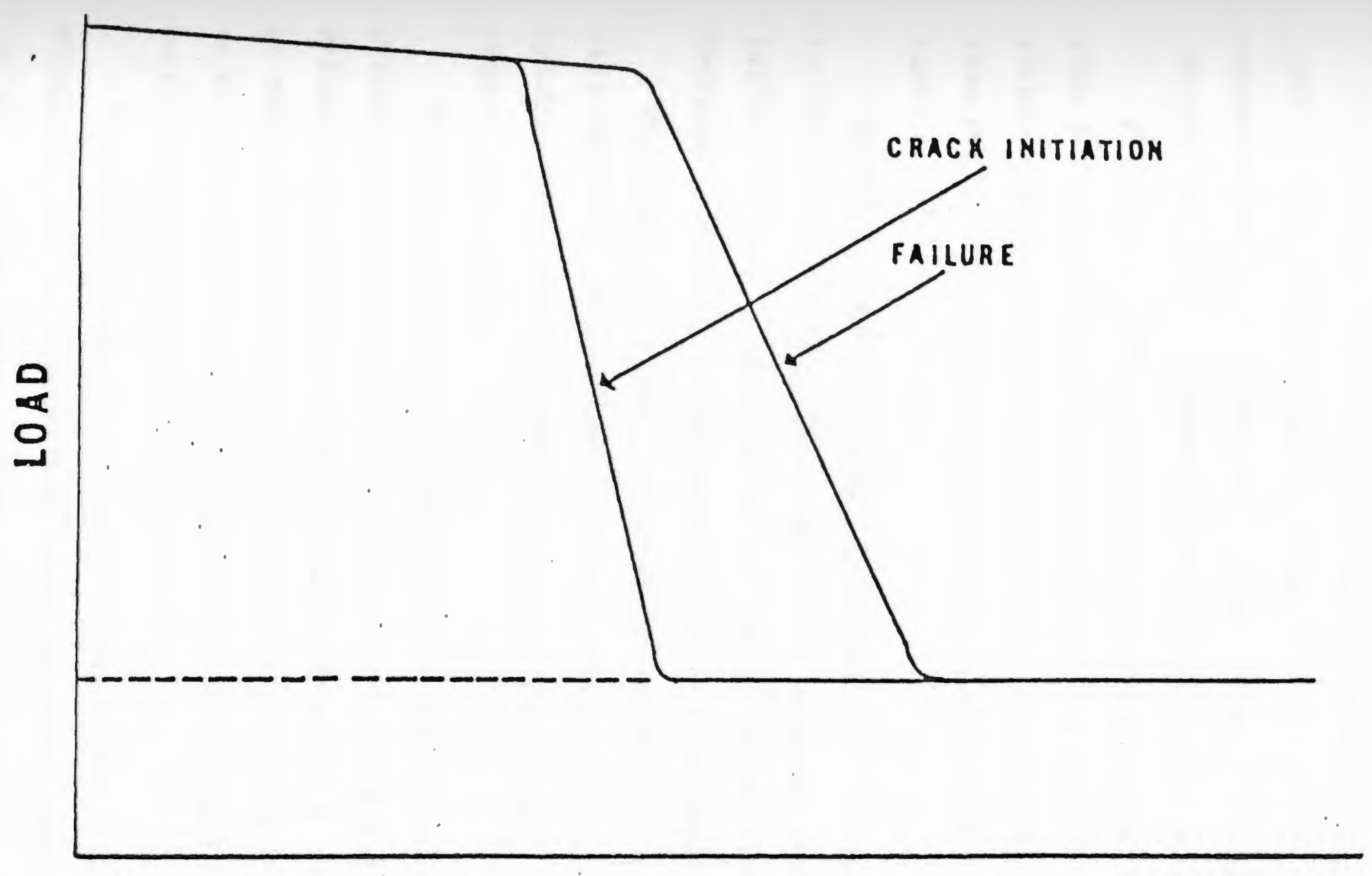

FIGURE 1. THE CHARACTERISTIC DIAGRAM OF LOAD VERSUS TIME FOR HYDROGEN INDUCED FAILURE 
Decohesion. This was originally proposed by Troiano (11) in 1960 and modified by Oriani (12) in 1972. The mechanism entails a reduction in the cohesive strength of the lattice due to interaction with dissolyed hydrogen.

Absorption. This was first proposed by Petch (13) in 1956 and then modified by others in 1970 to 1975. The absorption of hydrogen on a metal surface reduces the surface energy thus lowering the stress required for fracture.

Hydragen-stimulated plastic deformation. Beachem (14) in 1972 presented this mechanism, which supposes that the lattice is locally enhanced to be plastic due to absorbed hydrogen generating an increase in dislocation mobility.

Hydrogen-rich phase. This was presented by Westlake (15) in 1969. This mechamism assumes the presence of a hydride layer with different mechanical properties than that of the matrix.

Hydrogen-dislocation interactions. These were first presented by Bastien and Azou (16) in 1951 and subsequently discussed by others in 1968 and 1972. Hydrogen is assumed to react with dislocations to restrict dislocation mobility or to generate local high accumulations of hydrogen which both embrittle the lattice.

From these models it is evident that an all inclusive mechanism that is compatible with the observed phenomenon has yet to be developed and generally accepted. Regardless 
of the lack of a comprehensive mechanism of hydrogen embrittlement, the deleterious effects of hydrogen in steel are well documented.

There are many sources of hydrogen to cause subsequent embrittlement.

Hydrogen containment vessels provide the most direct source of hydrogen in metals. Hydrogen is exposed to metallic surfaces in molecular form in both high pressure and high temperature vessels.

The most potent source of hydrogen in metals is from an electrolytic reaction which cathodically deposits atomic hydrogen on the metallic surface. The fugacity (virtual pressure or concentration) of hydrogen in iron is $10^{5}$ to $10^{8}$ atmospheres (17).

Electrolytic reactions include the galvanic corrosion of iron in seawater and the corrosion reaction of steel in a hydrogen sulfide solution common in the petroleum industry. The reduction reaction in cathodic protection can lead to the evolution of hydrogen on the protected electrode.

Electroplating and chemical cleaning are also potent sources of hydrogen on a metal surface. In electroplating, large quantities of hydrogen can be co-deposited with the plated metal on the surface of the plated piece. A significant amount of hydrogen can diffuse into the piece being plated and can be trapped inside by the electroplated 
coating.

One way to solve the problem of hydrogen embrittlement is to cover the susceptable metallic surface with a coating that is impenitible to hydrogen. Effective barrier coatings for preventing the entry of hydrogen into a metal consist of coatings capable of surviving the service environment and that have a low permeability to hydrogen. There are three common types of barrier coatings: painted, metallic and ceramic.

Thick painted epoxy resin coatings were studied and shown to be comparable to a chromium coated steel plate for effectively reducing the susceptibility to hydrogen embrittlement (18).

Metallic coatings may be divided into three types: electroplated, hot dipped, and vapor deposited.

Electroplated coatings are either noble or sacrificial. Electroplated $\mathrm{Pt}, \mathrm{Cu}$ and $\mathrm{Ni}$ have been shown to significantly reduce the permeation rate of electrolytically charged hydrogen on iron membranes (19). Nickel has been shown to have a diffusivity approximately four orders of magnitude less than that of iron and, therefore, serves as an excellent diffusion barrier (20). Electrodeposited chromium, gold, and lead have also been shown to appreciably reduce the rate of embrittlement of steel plates (18).

Sacrifical metal coatings include zinc, cadmium, 
aluminum, and magnesium. Conflicting data exists in the literature regarding the effectiveness of these coatings toward increasing or reducing the susceptability of delayed failure due to hydrogen embrittlement (21). Much of this is due to the co-deposition of hydrogen in the plating process. Post plating bakeout procedures (22) should remove the bulk of entrained hydrogen to tolerable concentrations.

Hot dipped coatings include zinc and zinc aluminum alloys. These coatings have been found to cause hydrogen embrittlement by one investigator (23) and have been determined as an effective diffusion barrier by another (18). Attempting to justify the difference, Townsend (23) suspects that the thermal treatment employed to remove residual hydrogen after hot dip application may mobilize trapped hydrogen to embrittle the lattice while the hot dip coating prevents any hydrogen from escaping.

Vapor deposited coatings are commercially used, but they do not produce a strong mechanical bond on the base substrate (24) required for the electrochemical technique. Zinc, cadmium, aluminum and magesium may be vapor deposited on steel membranes and have been shown to be effecttive in reducing the susceptibility to hydrogen embrittlement (18).

Oxide coatings have shown a favorable potential for reducing hydrogen embrittlement for the past two decades. 
Tardif and Marquis (18) determined in 1962 that coppex oxide coated oyer a steel plate had only a slight reduction in fracture strengths when exposed to a hydrogen atmosphere and involved no measurable hydrogen on the exit side of the membranes. Huffine and Williams (25) confirmed the inverse thickness dependence on permeation rate at high temperatures for a variety of high strength metals with various oxide coatings. In all cases the oxidized metals ghowed a marked reduction in permeation rate at low temperatures compared to the clean metal, but the difference became less evident as the temperature was increased. The oxides resulted in approximately an order of magnitude reduction in permeation at high temperatures which the authors attributed to the lower diffusion rates through the oxide layers. In 1975, Perkins (26) presented a numerical analysis of oxide layer permeation of hydrogen which closely correlated with tested data. The model predicts a slightly non-linear dependence of permeation on $10 \mathrm{~g}$ pressure. Sherlock and Shreir (27) delved into the side effects of hydrogen entry during phosphate plating and determined the dependence on $\mathrm{pH}$, temperature and oxidants (28). The hydrogen permeation rate was found to have a linearly decreasing value with increasing $\mathrm{pH}$.

of these types of coating, metallic coatings are the most widely used, and of the metallic coatings, electroplated cadmium is frequently the coatings of choice by 
designers and specification writers of high strength fasteners (29). However, cadmium is recently receiving much discussion and attention, because of its toxicity in handling (25) and added expense in processing of the electroplating wastes (29). Current government regulations (30) regarding electroplating waste disposal have provided motivation to electroplaters and researchers to reevaluate cadmium as an amphoteric coating and to consider alternatives to cadmium. The following are the advantages and disadvantages of cadmium and its properties.

The advantages of electroplated cadmium are that cadmium has historically been used as a protective coating on high strength fasteners and other structural parts (31) and produces a uniform, adherent coating. An alternate method is vacuum deposition which requires the use of large chambers, has difficulties coating recessed areas, and has poor adhesion characteristics (31). The electroplated cadmium from a cyanide bath is a cost efficient technique that has been used for many years (29).

Cadmium is an anodic coating to ferrous substrates in aqueous environments (32). It serves as a sacrificial coating in the presence of holidays.

The wear resistant properties of cadmium are superior to alternative coatings (29). The ability to maintain close dimensional tolerances of the coating make cadmium the preferred galvanically active coating for many uses. 
The disadvantages of electroplated cadmium are primarily toxicity in handling and its susceptability to induce hydrogen generated failures.

It is common knowledge in the cadmium plating industry that hydrogen is generated and contained in cadmium plated parts $(23,31,33,34)$. This is attributed to plating inefficiencies which co-deposit hydrogen on the plating surface (21). It has also been exterisively studied to optimize plating baths to maximize their efficiencies.

Commercial practice specifies depositing a thin or porous coat of cadmium followed by a thermal bake out procedure, typically this is $3750 \mathrm{~F}$ for 8 hours or so (33). There are mixed opinions regarding the risk involved in cadmium plating high strength steel parts. While some have determined the process to be safe when properly followed by a bake out procedure $(33,35)$, others have observed a degradation in ductility of 4340 steel vacuum coated with a cadmium layer (34). This degradation was attributed to intergranular slow growth cracking which was postulated to be caused by the existence of a brittle sublayer under the cadmium/steel $i$ nterface in the absence of any hydrogen source.

Wanhill and deRijk (33) empirically determined that bright cadmium plated steel samples with a bake out post treatment are not susceptible to delayed failure. Others have found the hydrogen permeation rate to decrease by two 
orders of magnitude due to the application of the coating of cadmium (29).

The plating industry has recognized the severity of the disposal problem associated with electroplating wastes (34). Standard operating procedures of the past were to dispose the wastes in open pit or buried land fills and consider the problem solved. Cadmium as a trace metal in human consumption can lead to long term chronic disorders (36). Recent incidences around the country have shown that these wastes have filtered into underground water sources and have been suspect for the high rates of nervous system and intestinal disorders observed in the nearby localities $(30,37)$. These problems with cadmium have led to the consideration of alternatives to cadmium and the analysis of these alternatives.

There are various methods of determining the effectiveness of hydrogen barrier coatings. These variations in testing technique include the monitoring of total volume of hydrogen due to pressure differences in an evacuation chamber, (38) the monitoring of changes in physical properties due to the presence or absence of the coating in a hydrogen atmosphere (39) and the use of the electrochemical hydrogen permeation technique (40). Of these methods, the electrochemical permeation technique has been extensively used at various laboratories and has the most potential for the monitoring of low level changes in hydrogen evolution 
fluxes ( 41$)$.

B. Prior Work on Project

The electrochemical hydrogen permeation technique used in this study was first developed in 1962 by Devanathan and Stachurski (42). It has been subsequently modified by others and has been extensively employed by many researchers $(20,41,43)$. The technique entails potentiostatically monitoring the ionization current required to maintain the exit surfaces potential of a sample membrane to a preset electrochemical potential. When a hydrogen atom is exposed to the exit surface of the membrane, it is reduced to an ion due to that preset membrane potential. The hydrogen ion gains an electron, which alters the potential of the membrane. The potentiostat supplies enough current to the membrane to maintain the sample membrane at the preset potential.

A microammeter monitors the potentiostatic current supplied to the membrane, and Farraday's Law holds for converting the current flux to moles of hydrogen.

The system has its advantages and disadvantages. It is relatively inexpensive and simple to operate. Compared to other existing permeation techniques, it is extremely accurate at low flux levels.

The most notable disadyantages are a serisitivity to temperature near room temperature (41) and the difficulty 
in generating low hydrogen fluxes through the current charging circuit. Also, typical cell geometry designs include an o-ring seal between the sample membrane and the cell compartment. This o-ring presents a trap that prevents gas bubbles from escaping from the metal surface, thereby effectively reducing the wetted surface area.

The primary disadvantages of the electrochemical technique; namely the scatter of data between laboratories and the lack of reproducability within one laboratory have led to the development of an improved technique.

Table 1 summarizes some data on permeation rates through iron at room temperature. The high variation in permeation rates makes it difficult to accurately compare data. Past work at University of Rhode Island has been devoted to developing an improved technique (41) addressing specific problem areas. These include sample preparation, surface entry coatings, cell designs and temperature effects.

Variations in sample preparation techniques can lead to large variations in effective surface area at the inlet surface (43). Table II represents the schedule developed by University of Rhode Island researchers for preparing samples for repetitive performance.

Prior experience on iron has led to the use of palladium on the inlet and exit surfaces in order to prevent surface reactions in the electrolyte from altering the 
inlet flux or exit potential.

Pourbaix stability diagrams of iron in aqueous solutions, see Figure 2, indicate the wide ranges of oxide stability, and therefore, the necessity of providing a clean surface for hydrogen entry.

The Pourbaix diagram of palladium, Figure 3, indicates the range of thermodynamic stability of palladium. Palladium is, therefore, used to provide a clean entrance and exit surface for hydrogen permeation studies through iron.

Past studies $(41,43,44)$ have shown the effects of temperature on the permeation rates of hydrogen through iron near room temperature and have determined the necessity of accurately controlling a constant temperature.

These modifications to the existing methodologies provide an improved electrochemical technique capable of producing accurate repeatable data.

The existing body of data comparing the effectiveness of cadmium as a hydrogen barrier on iron or steel is limited and difficult to compare due to the diversity of testing techniques $(38,39,40)$. Davis and Gray have measured a hydrogen permeation rate of cadmium to be below the limits of their measurement technique, or as they say, nonexistant (38). Fischer and Jankowski (40) used the electrochemical technique to measure the effects of paint removers on cadmium coated parts by measuring the amount of hydrogen generated and permeated through an iron sample; 
TABLE 1: HYDROGEN PERMEATION RATE SUMMARY THROUGH IRON

\section{$\operatorname{AUTHOR}(\mathrm{S})$}

Kumnick, Johnson

Ansel, Miller, Hudson

Namboodhiri, Nanis

Dillard

Kuminick

$\stackrel{\rightleftarrows}{ \pm}$

Namboodhiri, Nanis

Beck, Bockris, Gensha, Subramanyan

Wach

Wach, Miodownick

Gileadi

Wach, Miodownick, Mackowiak

Shrier, Radhakrishnan

Bockris, Gileadi.

Beck, Bockris, McBreen,

Nanis

Bockris, Devanathan

Devanthan, Stachurski
YEAR

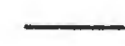

1974
1973
1972
1972
1972
1970

1970

1970

1969

1966

1966

1966

1966

1965

1962

1962

\section{MATERIAL}

Armco Iron

Armic Iron

Armco Iron

Zone Refined Iron

Armco Iron

Armco Iron

(Cold Rolled)

Armco Iron
Pure Iron
Pure Iron
High Purity Iron

High Purity Iron

Pure Iron

Armco Iron

Armco Iron

Armco Iron

(Single Crystal)

Zone Refined Iron

Armco Iron

Armeo Iron
APPARENT DIFFUSIVITY

$\left(\mathrm{cm}^{2} / \mathrm{sec} \times 10^{-5}\right)$

1.3

6.2

3. $86-17.20$

$7.0-7.8$

1. $1-1.5$

0.5

5.0

$0.135-4.1$

4.0-11.0

2.5

2.5

1.4

4.0

6.02

8.25

6.05

8.3

$3.5-8.9$ 


\section{TABLE II: SAMPLE PREPARATION TECHNIQUE}

1. Sample received from machine shop, measured and labeled.

2. 400 grit silicon carbide wet polish and rinse.

3. 600 grit silicon carbide wet polish and rinse.

4. $6 \mu$ diamond grit rough polish and rinse.

5. $1 \mu$ aluminum oxide polish and rinse

6. Optical microscope inspection of surface integrity.

7. $.05 \mu$ aluminum oxide polish and rinse

8. U1trasonic cleanse for 30 minutes. 


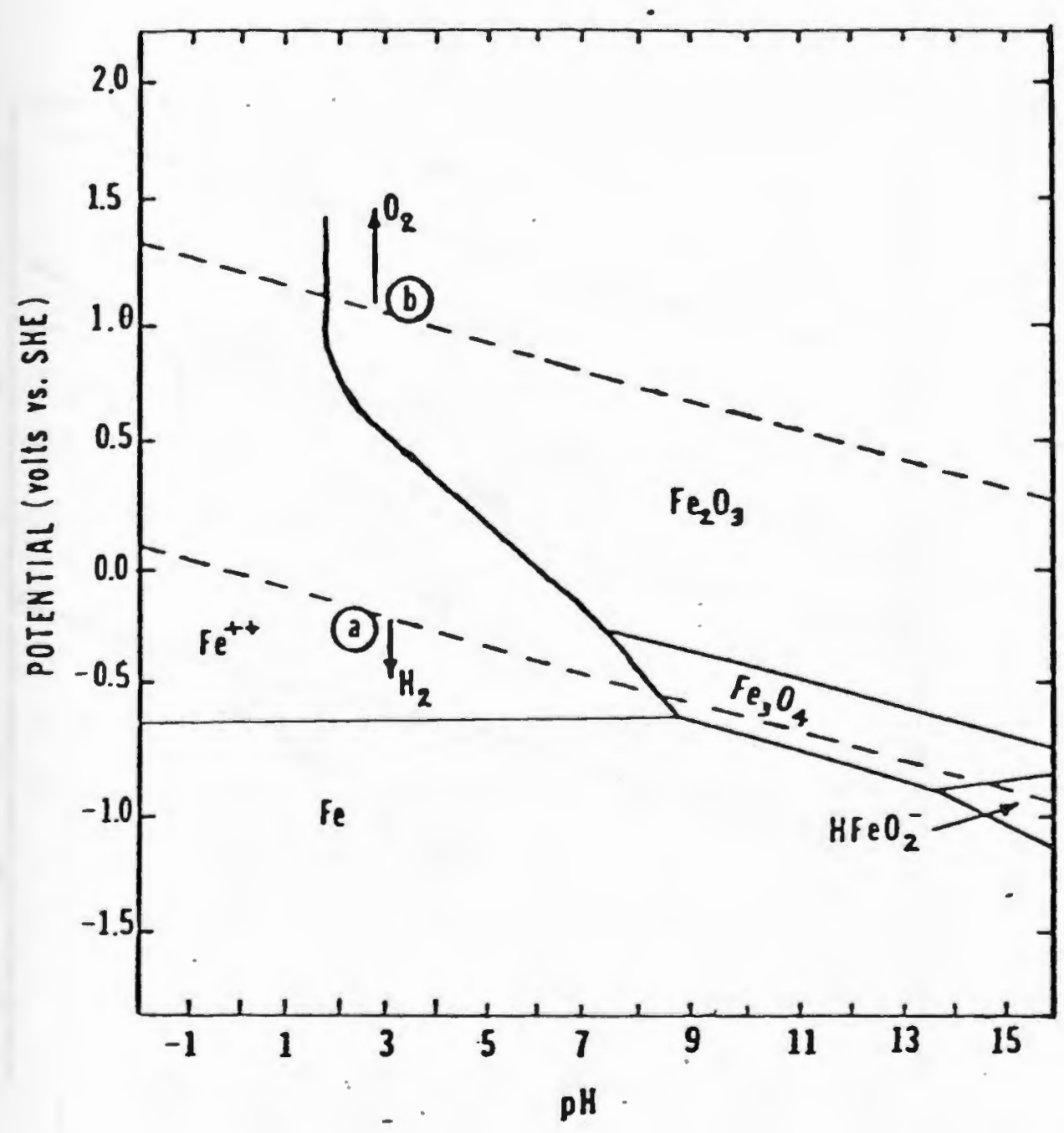

FIGURE 2. POURBAIX DIAGRAM FOR IRON 


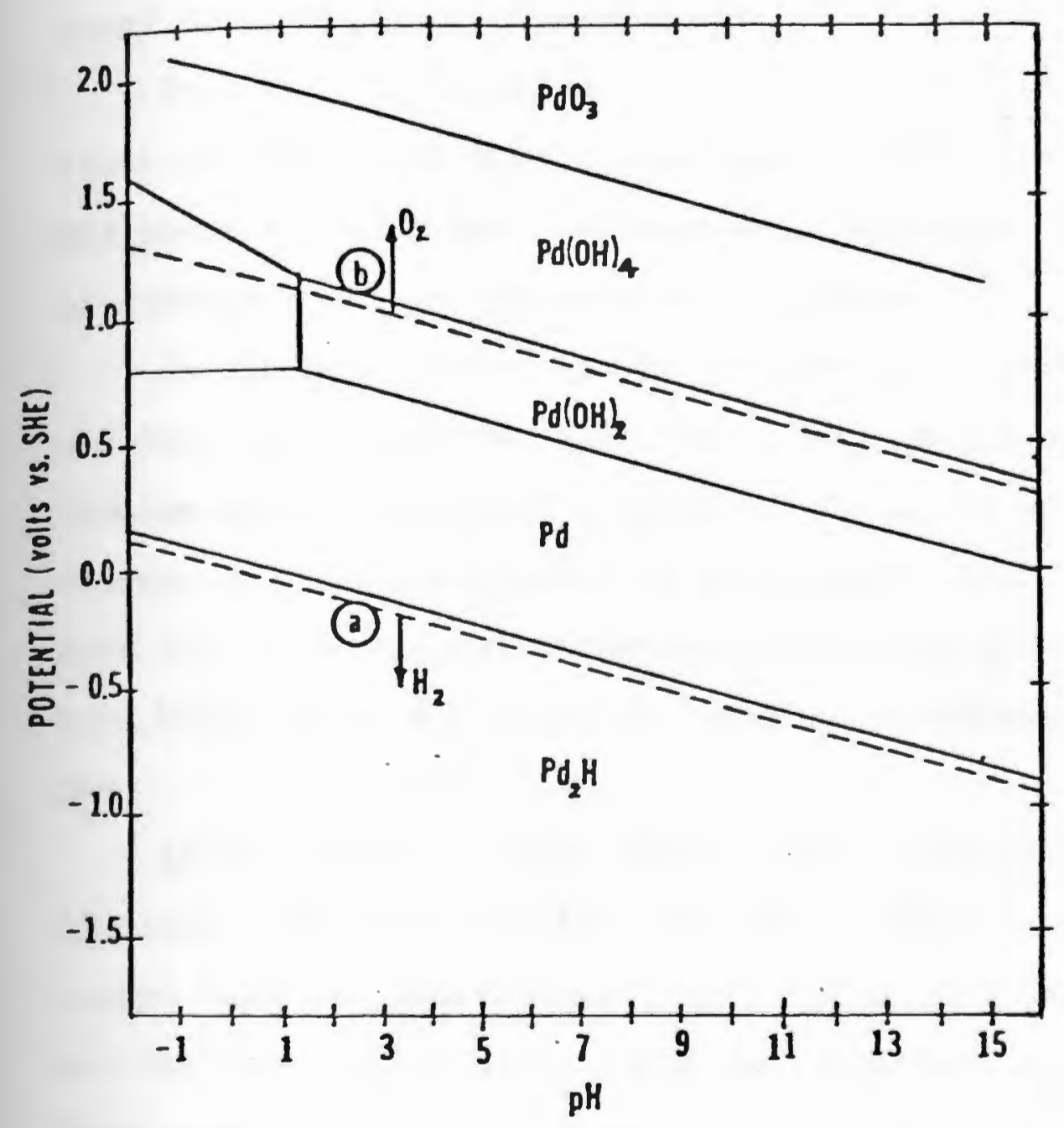

FIGURE 3. POURBAIX DIAGRAM FOR PALLADIUM 
they only indirectly measured permeation rates. Serate systematically measured the detrimental mechanical effects of various thicknesses of cadmium coated parts when exposed to hydrogen atmospheres (39).

From this information it is clear that wide variations in testing techniques and results have been observed and there exists a need to accurately determine the effects of cadmium coatings on ferrous substrates.

Anodic metal alternatives to cadmium consist of zinc, aluminum and magnesium. Zinc has a similar problem to cadmium when plated from a cyanide bath as it will codeposit significant quantities of hydrogen (21). However, zinc can be successfully plated from a high efficiency acid bath (45) with a reduced level of co-deposited hydrogen.

Aluminum can be vapor deposited on a metal part (45). Aluminum also has potential for coating from an electroplated bath on certain metals (46). The vapor deposition and the electroplating aluminum coatings both are free from co-deposition of hydrogen $(45,46)$ however, both aluminum and zinc create stronger galvanic couples when coupled with steel as compared to cadmium. This potential difference could result in an increased production of hydrogen at voids due to the galvanic coupling.

Because of its greater rest potential difference, from steel, and its greater reactivity, magnesium poses even a 
greater threat to the production of hydrogen during service corrosion than does cadmium. It is not a likely alternative to cadmium.

\section{Purpose}

The purpose of this thesis is to quantify the effectiveness of electrodeposited cadmium for restricting the entry of hydrogen in a metal by using the electrochemical hydrogen permeation technique to monitor the hydrogen permeation rate through a metallic membrane without and with various thicknesses of a cadmium coating.

The project is divided into two major parts. The first part is to develop a methodology to plate the exposure samples and then successfully generate hydrogen evolution flux transients on the samples. This will provide the technique and samples to do the second part of the project.

The experimental effort, second part of the project, is broken into three parts. The first part is to determine the effects of the iron substrate on the hydrogen permeation rate. This will be the base line for comparisons with cadmium coatings, and will also verify the repeatability with previous U.R.I. experiments.

The second part is to determine the effects of various iron substrate thicknesses with a constant cadmium coating layer on the inlet side. 
The third part is to vary the thickness of the cadmium coating and determine the effects of this variation on the permeation rates at constant inlet charges. 
CHAPTER 2

EXPERIMENTAL

\section{A. Plating Development}

This chapter details the development of the methodology, techniques and equipment, slected for the use in this project. A base substrate was chosen as the foundation on which various thicknesses of cadmium were deposited on one side. Both sides of the sample were then coated with palladium as shown in Figure 4. The samples were then placed in the hydrogen permeation exposure apparatus for the various tests.

Early in the course of this project, it was decided to use an existing commercially prepared cyanide cadmium electroplating bath instead of preparing a new bath. This was done in order to attempt to replicate an industrial electroplating process.

This approach presented many unforeseen difficulties as the commercial baths obtained had been extensively used and required refinement and purification in order to achieve the quality of electroplate desired. The technique developed entailed a chemical analysis of the bath followed by organic and inorganic impurities removal. Final refinement consisted of brightness and efficiency control with the Hull cell, which is described in detail later in this chapter. 


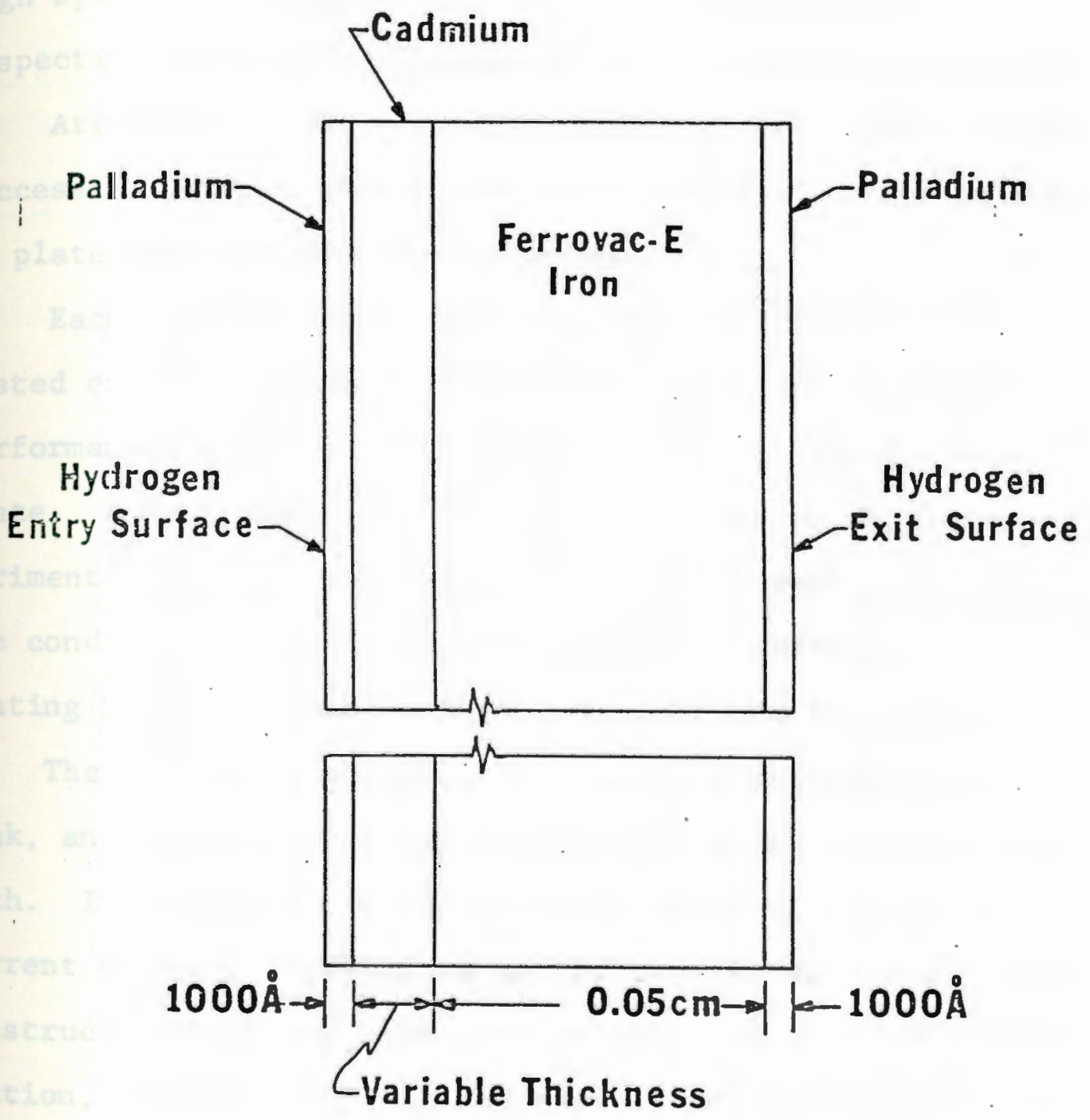

FIGURE 4. TYPICAL SAMPLE MEMBRANE 
There were two types of electroplating solutions used successfully in this project and two solutions that were unsuccessful in their plating adherance. The acceptable solutions were a standard cadmium cyanide bath and a new high speed palladium bath. Table III and Appendix II respectively list the composition of these two solutions.

Attempts to use a cyanide and acid zinc bath were unsuccessful as were the efforts by a commercial plater (46), to plate iron samples with aluminum.

Each electroplating bath used in this project was tested experimentally and analytically to optimize the performance of the bath to achieve the desired electroplate. A Hull cell (Appendix III) is used to do the experimental testing. Specifically, it is used to determine the condition of the bath, the brightest current-density plating range, and the effects of additions to the bath.

The Hull cell consists of a small electroplating tank, an anode, a test panel cathode and the electrolytic bath. It is used to produce a wide range of cathodic current density depositions on the test panel. The tank is constructed with a square section adjacent to a triangular section, see Figure 5, of the tank. A large surface area anode is located at the square section end and the test panel is adjacent to the sloping side of the triangular end. The edge of the test panel nearest the anode receives the greatest current density deposits. The furthest 
TABLE III: CADMIUM BATH COMPOSITION

\begin{tabular}{|c|c|c|c|c|c|c|}
\hline Component & $\mathrm{CdO}$ & $\mathrm{Cd}$ & $\mathrm{NaCN}$ & $\mathrm{NaOH}$ & $\mathrm{NaCO}_{3}$ & Brightener* \\
\hline $0 \mathrm{z} / \mathrm{Ga} 1$ & 0 & 3 & 17.7 & 1.5 & 8.6 & 1.28 \\
\hline
\end{tabular}

"Brightener used is Enthone, Inc.'s "Enthobrite CTD 904" See Appendix $V$ for data sheet 


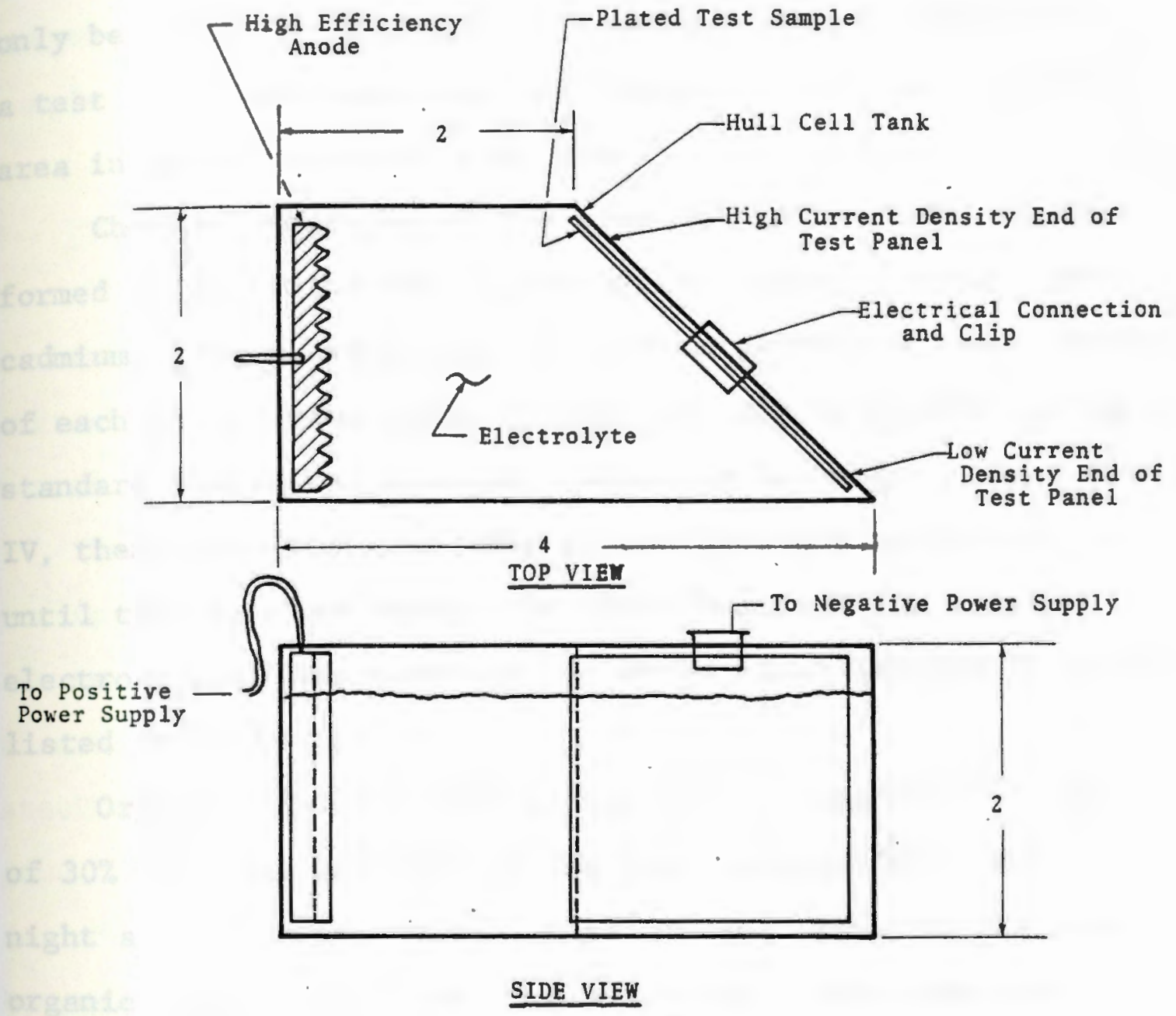

FIGURE 5. THE HULL CELL 
end receives the least amount of deposition with a uniform scan in between. Comparison with calibration charts can give rough estimates of the current densitites of specific sections on the rest panel, but exact determination can only be found by plating at a constant current density on a test strip and comparing the results of the strip to the area in question on the test panel.

Chemical analysis of the cyanide cadmium bath was performed to determine the percentage of sodium cyanide, free cadmium, sodium hydroxide, and sodium carbonate. The amount of each of the components in question was determined using standard analytical chemical titrating techniques, Appendix IV, then additions were made to the bath and rechecked until the bath was within the specifications for cadmium electroplating described in the Metal Finishing Handbook as listed in Table III.

Organic impurity removal was done by mixing in $4 \mathrm{ml} / 1$ of $30 \%$ hydrogen peroxide to the bath and agitating overnight at room temperature. This process would oxidize any organic impurity to a solid precipitate. This precipitate, along with any other suspended particulate matter, was filtered out through an activated carbon filter.

Metallic impurities were removed by electrolysis of the bath at low current densities, $0.9 \mathrm{ma} / \mathrm{cm}^{2}$ (5 ASF), for 10-12 hours.

The brightness of the electroplate was controlled by 
using the Hull cell and small additions of commercially prepared brightness solutions, see Appendix V, to determine the optimum amount of the addition agent requried for the bath. The Hull cell was used to determine the optimum current density to plate the hydrogen permeation exposure samples.

\section{B. Hydrogen Permeation System}

The hydrogen permeation process system consists of the combined use of the sample preparation techniques, the plating procedures to produce a sample membrane and the use of the electrochemical cell.

Ferrovac "E", a double vacuum arc remelted high purity magnetic purpose iron, was used as the base substrate in the sample membrane. Table IV presents the chemical composition of the metal used. The as-rolled bar stock was cut along the longitudinal grain axis and machined into $2.54 \mathrm{~cm}$ square plates of various thicknesses (see Figure 4). Ferrovac " $E$ " was chosen as the substrate because of its high purity and expected reproductibility between replicate samples.

The samples, as received from the machine shop, were surface ground to an approximate surface roughness of 120 rit paper. They were then rough polished on silicon carbide water Iubricated discs of 350 and grit grid successively, followed by a 6 micron diamond wheel medium polish. 
TABLE IV: FERROVAC "E" COMPOSITION*

\section{Element}

Al uminum

Carbon

Chromium

Cobalt

Copper

Managanese

Molybdenum

Nickel

Phosphorus

Silicon

Sulphur

Tin

Tungsten

Vanadium

Oxygen

Iron
Weight $\&$

0.01

0.005

0.001

0.002

0.002

0.001

0.005

0.007

0.003

0.006

0.005

0.004

0.01

0.004

0.0078

Balance

* Analysis supplied by Colt Industries, Crucible, Inc., Speciality Metals Division, Pittsburgh, PA. 
The final polish was a 0.05 micron aluminum oxide polish on a nylon polishing disc. The final polish was checked with a light microscope to insure a uniform scratch pattern.

Grease removal entailed emersion of the samples in a commercially prepared solution (47) in an ultrasonic tank for $1 / 2$ hour. This was followed by a distilled water rinse, then acetone rinse, and air drying before placing in a desiccant-filled container for storage.

Prior to plating, the samples were masked (see Appendix VI), and then were chemically treated for oxide removal and for surface activation to acquire a more uniform appearing plate. This entailed dipping the samples in acetone, methano 1 and a $30 \%$ solution of hydrochloric acid each followed by a distilled water rinse then air drying after the last rinse. Table $\mathrm{V}$ summarizes the sequence of steps performed for sample degreasing, oxide removal, and surface activation. The sample was immediately placed in the electroplating bath.

The plating system developed consisted of a University of Rhode Island constructed potentiostatically controlled constant current power supply in series with an automatic timer. With this system it was possible to coulombmetrically calculate and set the desired plate thickness. The plating bath was held at a constant temperature on a hot plate and agitated with a magnetic stirrer. Figure 6 shows the plating system used. 
Early efforts with palladium plating on cadmium were unsatisfactory and led to the use of the high speed palladium bath shown in Appendix II. Because of the high reactivity of the pure iron in the acid bath, it was necessary to flash on a thin film of palladium to seal the iron from the palladium electrolyte. In order to produce this thin flash, the samples were electrically connected to the power supply and dipped into the palladium bath, with the power on, for approximately one second of plating at 9.0 $\mathrm{ma} / \mathrm{cm}^{2}$ (50 ASF). This process was followed by a 30 second plate at $0.9 \mathrm{ma} / \mathrm{cm}^{2}$ (5 ASF) in order to deposit $1000 \mathrm{~A}$ of palladium on the iron. Appendix VIII shows the calculations used to determine the plating current and time for the various plates.

The Hull cell was employed to determine a bright and efficient current density range to plate the palladium on the different metals. Table X summarizes the schedule used of palladium over iron and the schedule of palladium over cadmium.

Many attempts were made to plate palladium on zinc; none were successful. A cyanide $z$ inc and a non-cyanide acid $z$ inc plate were tried as the base along with various types of surface activation. Three types of palladium were tried, but, again, none were successful.

The surface integrity of the various electroplates was checked using a scanning electron microscope in the 
TABLE V: SAMPLE CLEANING AND PLATING SCHEDULES

1. Polish both sides to 0.1 surface roughness

2. Ultrasonic clean for 45 minutes

3. Mask numbered side of sample

4. Degrease with methanol rinse

5. Distrilled $\mathrm{H}_{2} \mathrm{O}$ rinse

6. $5 \% \mathrm{HCl}$ dip for surface activation

7. Distilled $\mathrm{H}_{2} \mathrm{O}$ rinse

8. Plate in Pallaspeed bath Flash a $347 \mathrm{ma}(187 \mathrm{mv})$ for $1 \mathrm{sec}$. Plate a $35 \mathrm{ma}$ (18mv) for $30 \mathrm{sec}$.

9. Distilled $\mathrm{H}_{2} \mathrm{O}$ rinse

10. Air dry

11. Remove and discard mask

12. New mask on bare side

13. Degrease with methanol rinse

14. Distilled $\mathrm{H}_{2} \mathrm{O}$ rinse

15. $30 \% \mathrm{HCl}$ dip (surface activation)

16. Distilled $\mathrm{H}_{2} \mathrm{O}$ rinse

17. Let sit in cadmium bath for 2 minutes

18. Plate in cadmium bath @ $25 \mathrm{ASF}, 174 \mathrm{ma}$ ( $92 \mathrm{mv}$ ) for 4 mins. 4 sec.

19. Rinse in cold tap water

20. Distilled $\mathrm{H}_{2} \mathrm{O}$ rinse

21. $1 \mathrm{M} \mathrm{HCl}$ dip

22. Distilled $\mathrm{H}_{2} \mathrm{O}$ rinse

23. Sit in Pallaspeed bath for 30 sec. 


\section{TABLE $\mathrm{V}$, CONTINUED}

24. Plate pallaspeed on cadmium at 5ASF, 35ma (18mv) for $40 \mathrm{sec}$.

25. Distilled $\mathrm{H}_{2} \mathrm{O}$ rinse

26. Remove and discard mask

27. Acetone, Methanol, then distilled $\mathrm{H}_{2} \mathrm{O}$ rinse and air dry. 


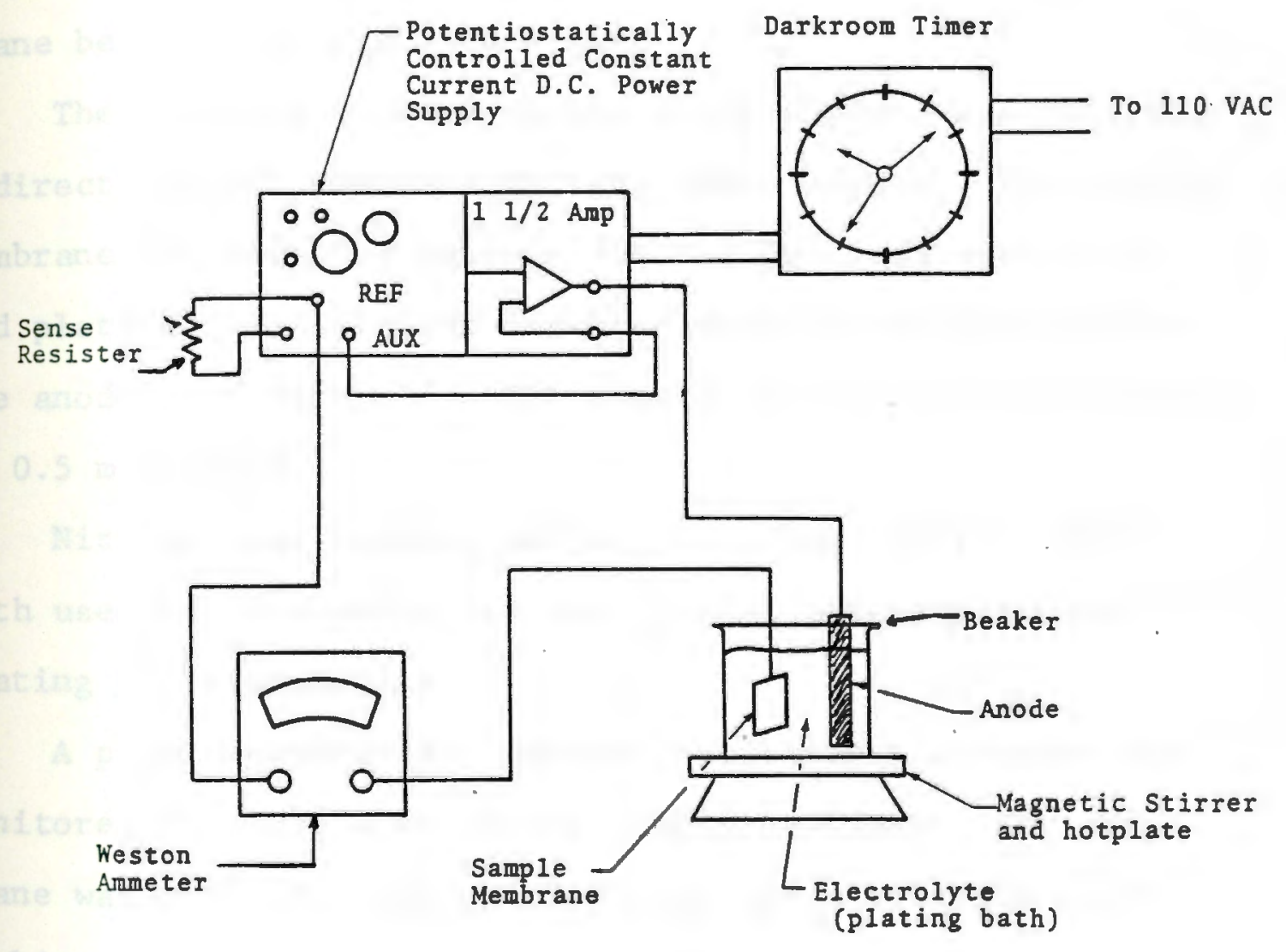

FIGURE 6. THE ELECTROPLATING SYSTEM 
University of Rhode Island's Department of Chemical

Engineering. Appendix I shows representative pictures of the exposed and unexposed surfaces of palladium on iron, cadmium on iron and palladium on cadmium, respectively, at the magnifications listed.

The elctrochemical cell consisted of a charging (inlet) chamber, a potentiostatic (exit) chamber and a sample membrane between the two, see Figure 7 .

The hydrogen charing on the inlet surface was done via a direct-current constant-current power supply. The sample membrane was made the cathode for the hydrogen evolution and platinum clad niobium expanded metal strip was used as the anode, see Figure 7. The sample membranes were charged at 0.5 milliamps.

Nitrogen gas purging and magnetic bar stirring were both used to thoroughly mix and prevent oxygen from contaminating the electrolyte.

A potentiostatically controlled, three electrode cell monitored the exit side of the sample membrane. The membrane was made the working electrode and a platinum clad niobium strip was used as the auxillary electrode. A calomel reference electrode monitored the membrane potential set at $-250 \mathrm{mV}$ relative to the calomel electrode via a Luggin probe, see Figure 8.

A micro ammeter in series with the working electrode (sample) measures the current from the potentiostat. 


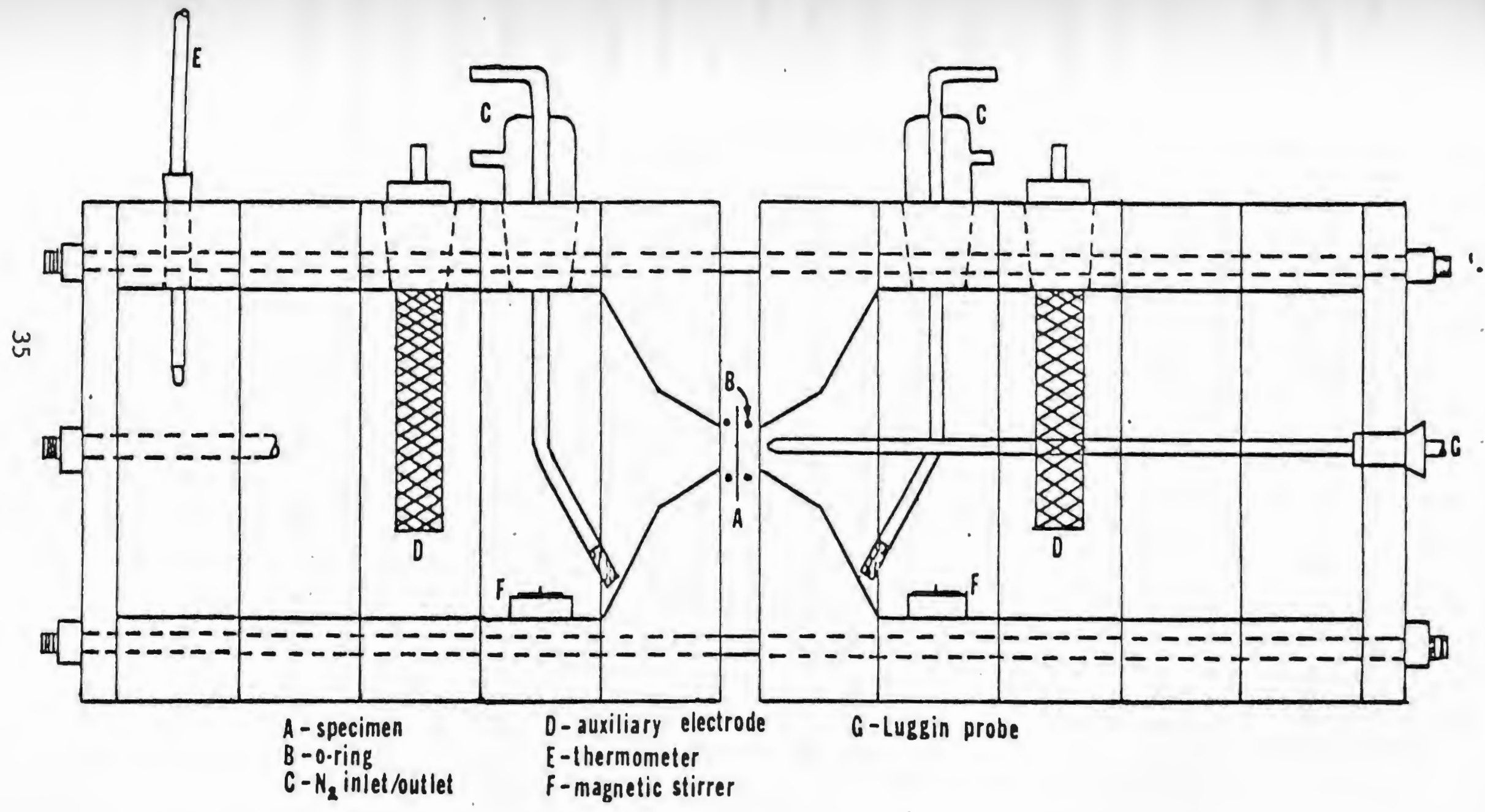

FIGURE 7. HYDROGEN PERMEATION CELL USED IN THIS INVESTIGATION 
while a voltage converter in parallel with the ameter drives a strip chart recorder for continuous permeation data monitoring.

The electrolyte was a $0.2 \mathrm{~N}$ solution of sodium hydroxide for both the inlet and exit chambers. Each side of the cell had approximately 1 liter of solution in the compartment.

\section{Experimental Plan}

Table VI summarizes the exposure plan used in this project. The first task was to determine the effects of electroplated palladium thickness on the hydrogen diffusion rate through a palladium-iron-palladium composite.

Next, the effects of various thickness of the iron substrate were monitored while using a constant thickness of cadmium and palladium electroplates.

Finally, the effects of various cadmium electroplate thicknesses were determined while maintaining a constant iron thickness.

Previous tests on cadmium plated samples have shown that blistering occurs when the cadmium plated surface is positioned on the exit side of the sample membrane (38). 


\begin{tabular}{|c|c|c|c|}
\hline Group & $\begin{array}{c}\text { Base } \\
\text { Thickness } \\
\text { (mils) }\end{array}$ & $\begin{array}{c}\text { Cadmium } \\
\text { Thickness } \\
(1 / 10 \text { mils })\end{array}$ & Description \\
\hline I & 23 & None & $\begin{array}{l}\text { Confirm equipment } \\
\text { performance } \\
\text { Baseline data for } \\
\text { comparisons }\end{array}$ \\
\hline II & 25 & None & $\begin{array}{l}\text { Determination of } \\
\text { substrate thickness } \\
\text { effects }\end{array}$ \\
\hline III & 22.5 & 2 & $\begin{array}{l}\text { Determination of } \\
\text { Cadmium thickness } \\
\text { effects }\end{array}$ \\
\hline
\end{tabular}

NOTE: all samples have $1000 \AA$ of Palladium on both sides 


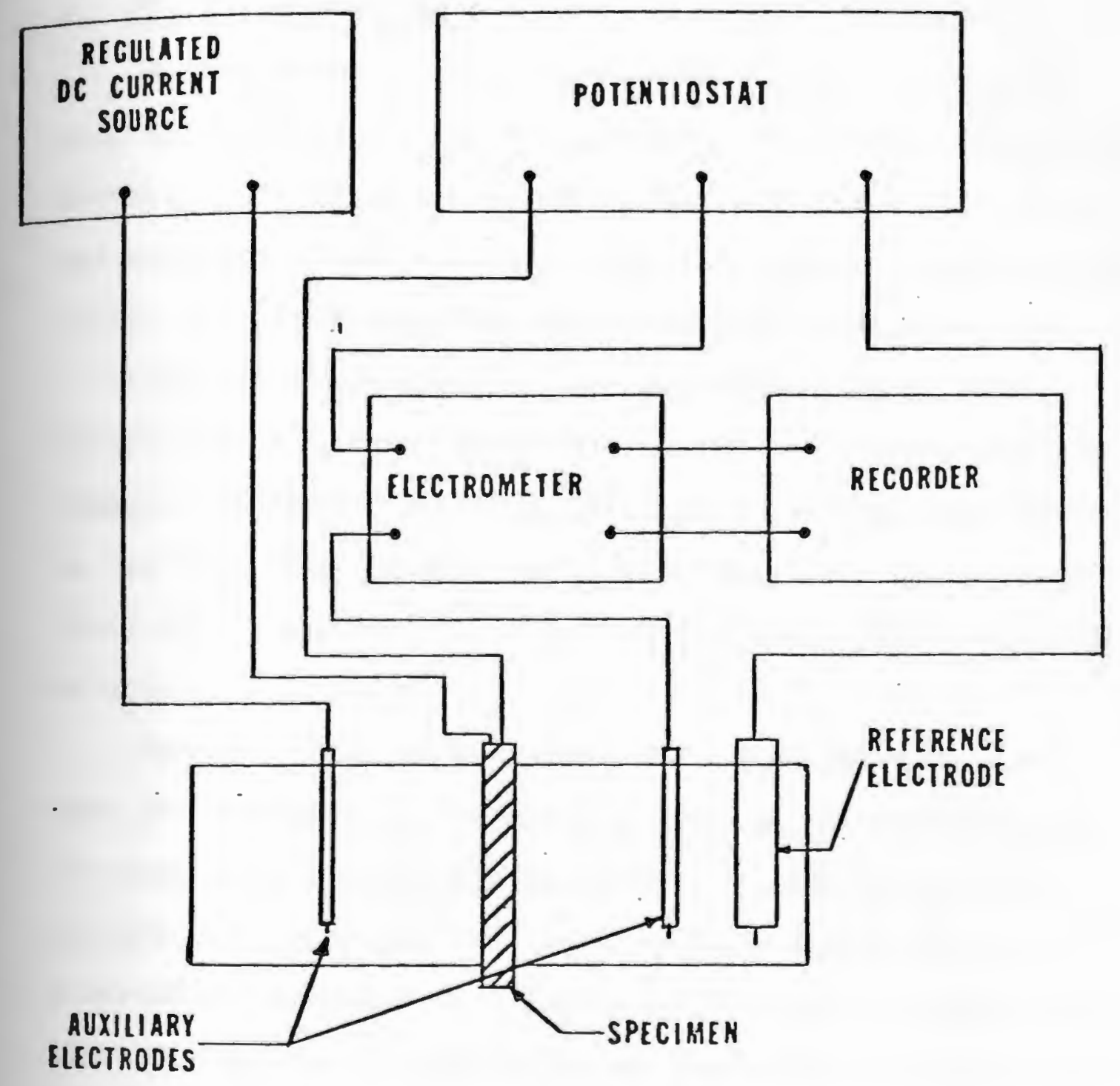

GURE 8. BLOCK DIAGRAM OF THE ELECTROCHEMICAL HYDROGEN PERMEATION APPARATUS USED IN THIS INVESTIGATION 
CHAPTER 3

RESULTS

\section{A. Plating Development}

As discussed in the experimental chapter, the first step in the project was to replicate the results of earlier investigators in order to verify the equipment performance and technique repeatability. However, prior to these first tests, new electroplating solutions had to be developed.

The resulting solution of numerous attempts with various other cadmium solutions is the electroplating bath composition listed in Table III. This solution was chosen as the best bath to use on the iron samples. Appendix V lists the operating specification for this cadmium cyanide solution.

Technic, Inc. of Cranston, R.I., had recently developed and marketed a high speed palladium bath which adhered acceptably to the cadmium surface. However, a high current density flash was required in order to get an acceptable coating on the bare iron surface. Appendix II lists the makeup of the Palladium bath and the operating specifications for this bath.

\section{B. Tests with Iron Substrate}

Following the development of plating baths and procedures, the next step was to replicate the permeation 
experiment of Jones, using iron samples coated only with palladium. Figure 9 shows the results of this test with two replicate samples. Both the data of Figure $g$ and Jones data were obtained with inlet charing currents of $1.0 \mathrm{ma}$.

Since all of the data using samples with a cadmium coating was taken at a charging rate of $0.5 \mathrm{ma}$, an uncoated, i.e. no cadmium, reference sample was run at the $0.5 \mathrm{ma}$ charging rate. Figure 10 shows data from the replicate samples of iron with only palladium on the inlet and exit surfaces. This data was the reference for comparison with the samples coated with cadmium.

\section{Effects of Anodic Coatings on Substrate}

Following the tests on palladium-iron-palladium samples, experiments were run with palladium-cadmium-ironpalladium samples. The first group of these were run at a constant cadmium plate thickness and various iron substrate thicknesses. Table VI details the test samples used in that group and Figures 11 through 13 are the plots from these respective tests.

After the tests at a constant cadmium plating thickness, a second group of experiments was run with a constant iron substrate thickness and various cadmium plating thicknesses. Both the inlet and exit surfaces were coated with palladmium. Table VI also lists the substrate and 


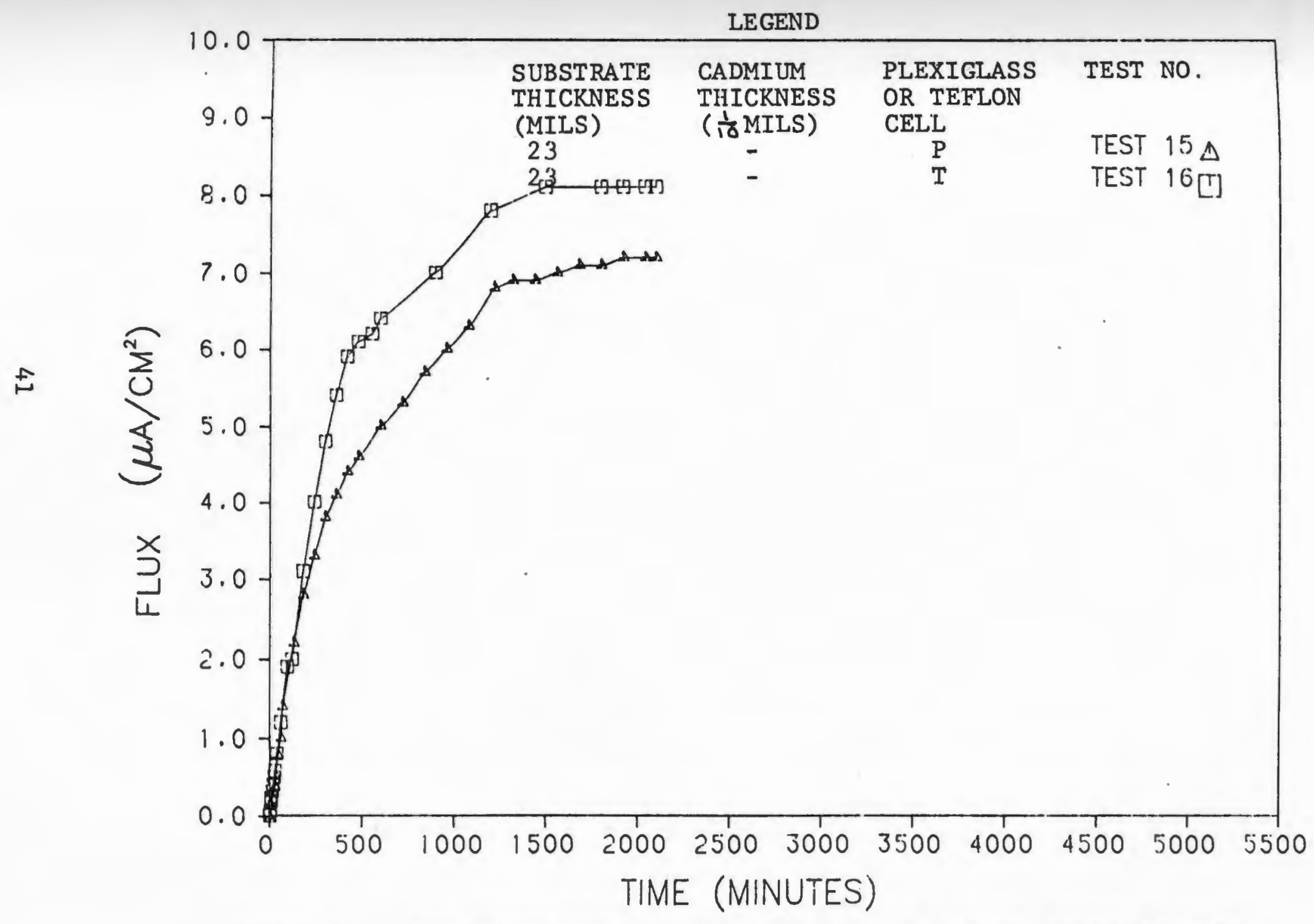

FIGURE 9. FLUX TRANSIENTS WITHOUT CADMIUM AT 1.0 MA CHARGING RATE 
coating thicknesses for these tests and Figures 14 and 15 are the plotted permeation curves for these respective tests. 


\section{LEGEND}

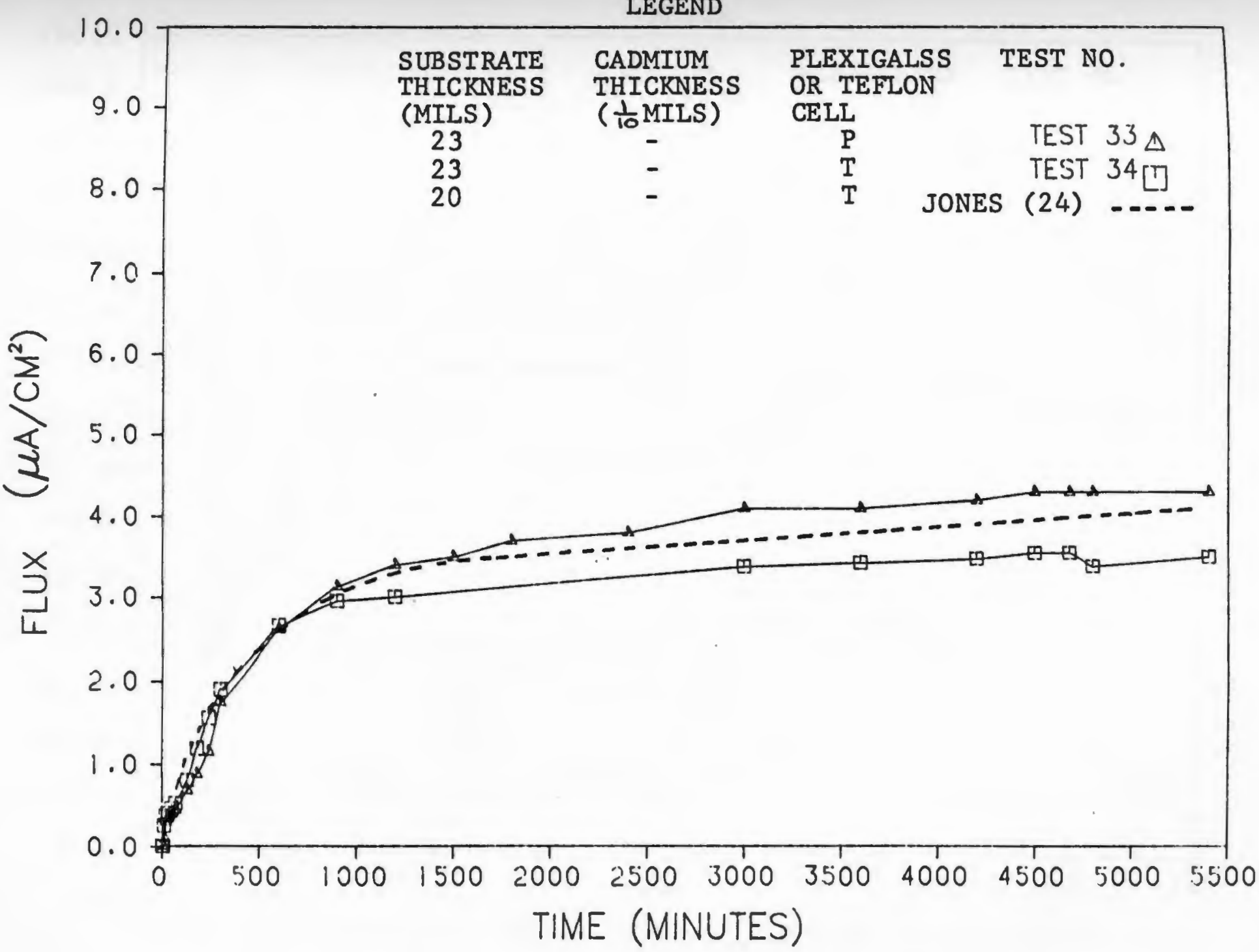

FIGURE 10. FLUX TRANSIENTS WITHOUT CADMIUM AT 0.5 MA CHARGING RATE 


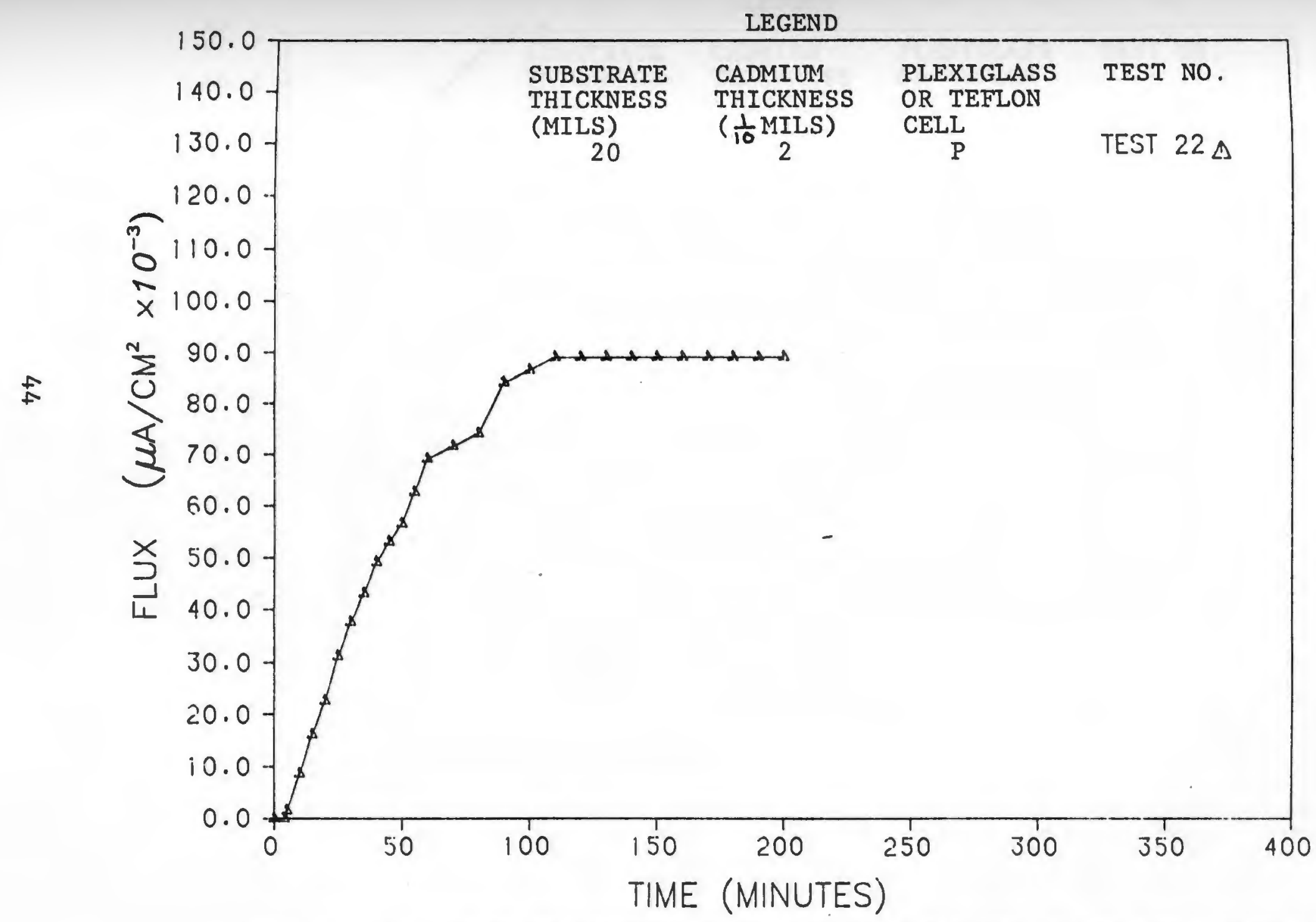

FIGURE 11. FLUX TRANSIENTS WITH 0.2 MILS CADMIUM ON 20 MILS IRON AT 0.5 MA CHARGING RATE 
LEGEND

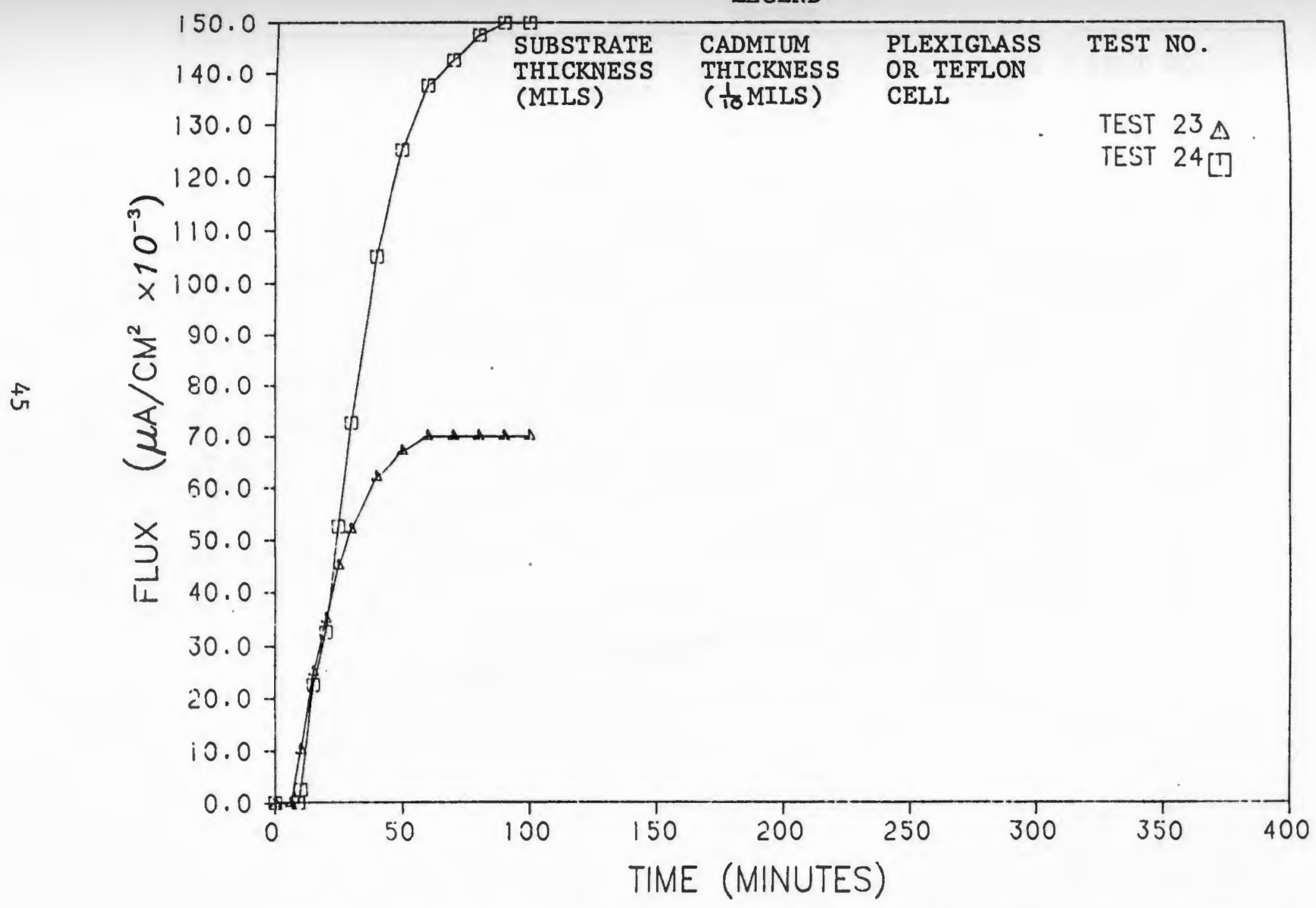

FIGURE 12. FLUX TRANS IENTS WITH 0.2 MILS CADMIUM ON 40 MILS IRON AT 0.5 MA CHARGING RATE 


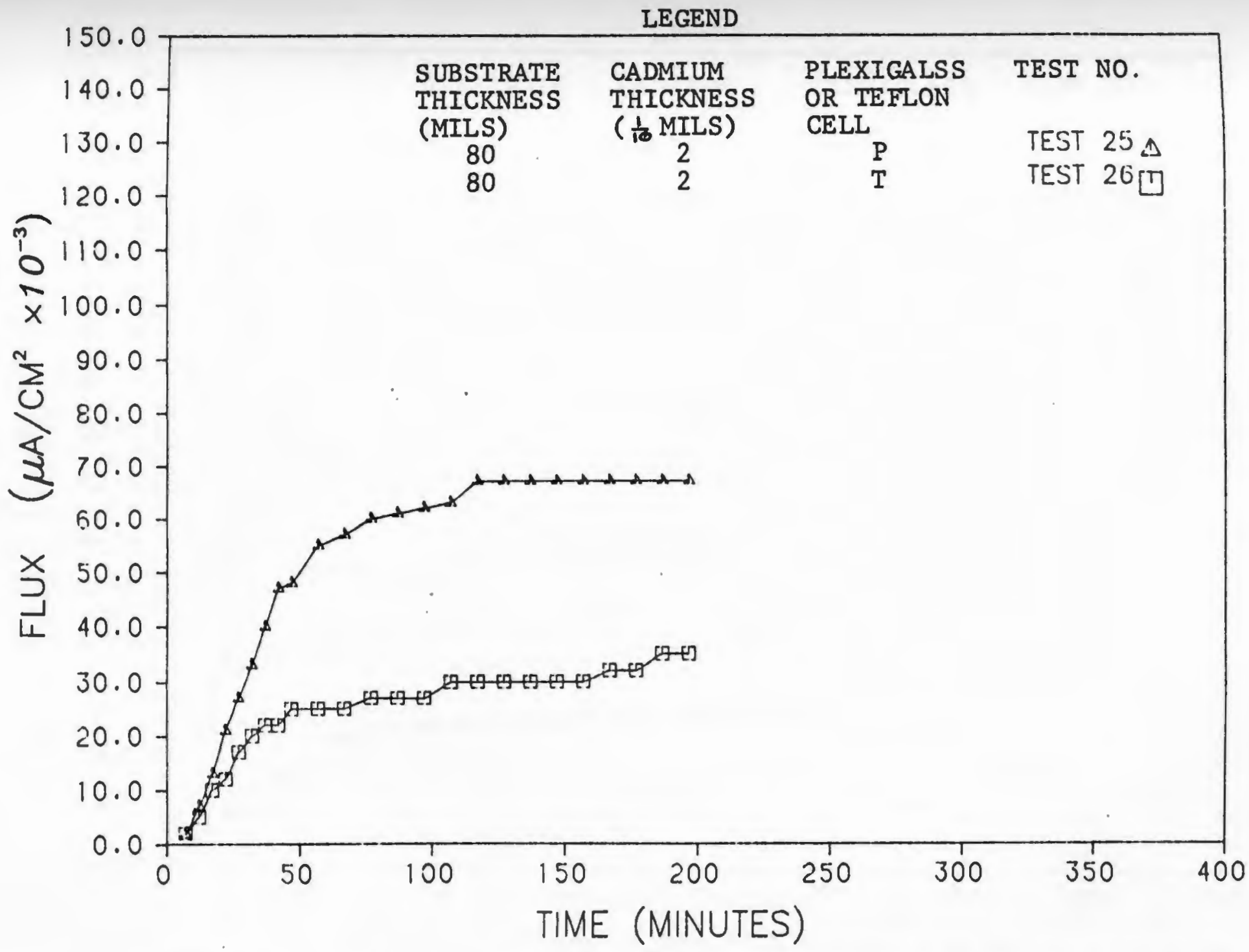

FIGURE 13. FLUX TRANSIENTS WITH 0.2 MILS CADMIUM ON 80 MILS IRON AT 0.5 MA CHARGING RATE 
LEGEND

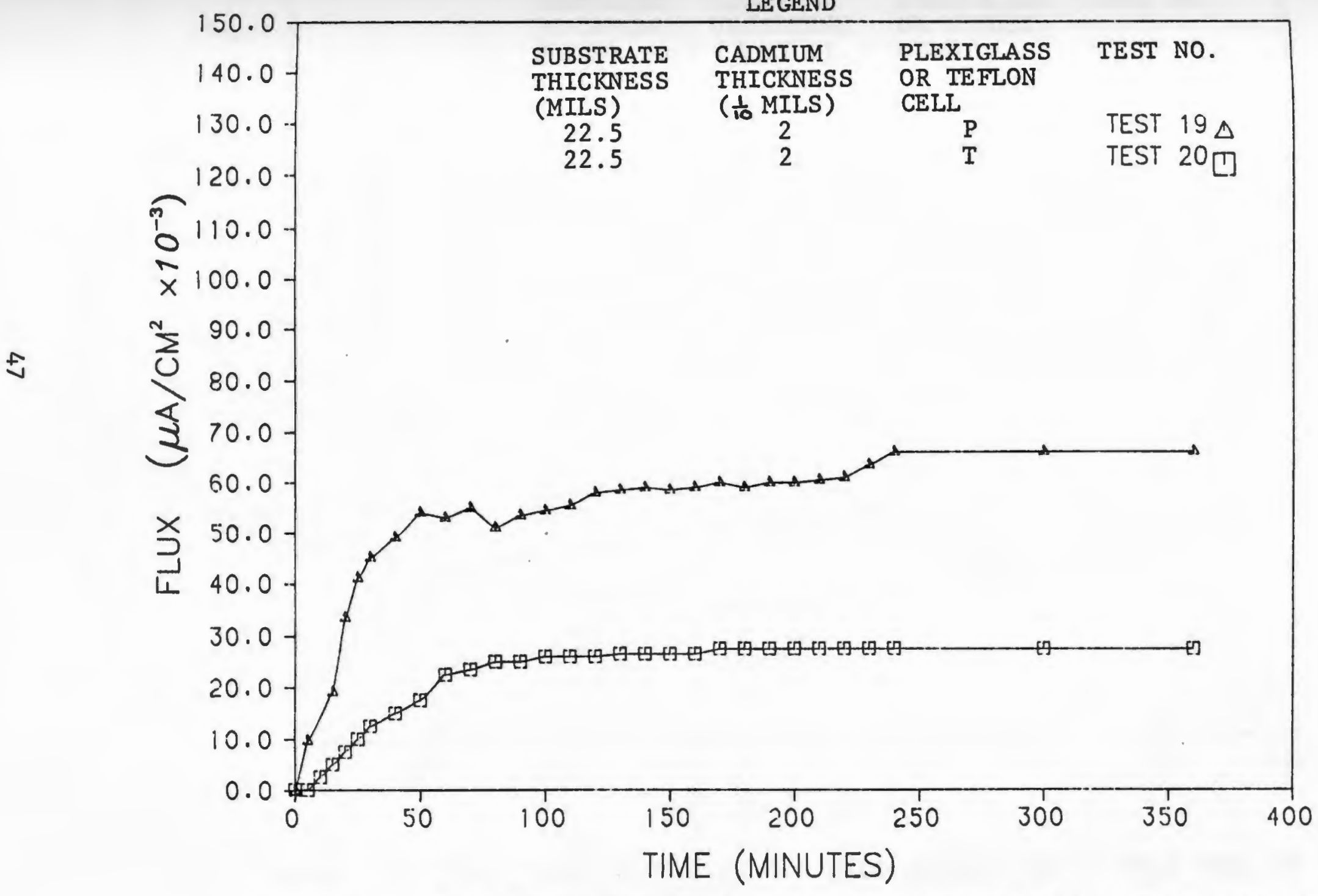

FIGURE 14. FLUX TRANSIENTS WITH 0.2 MILS CADMIUM ON 22.5 MILS IRON AT 0.5 MA CHARGING RATE 


\section{LEGEND}

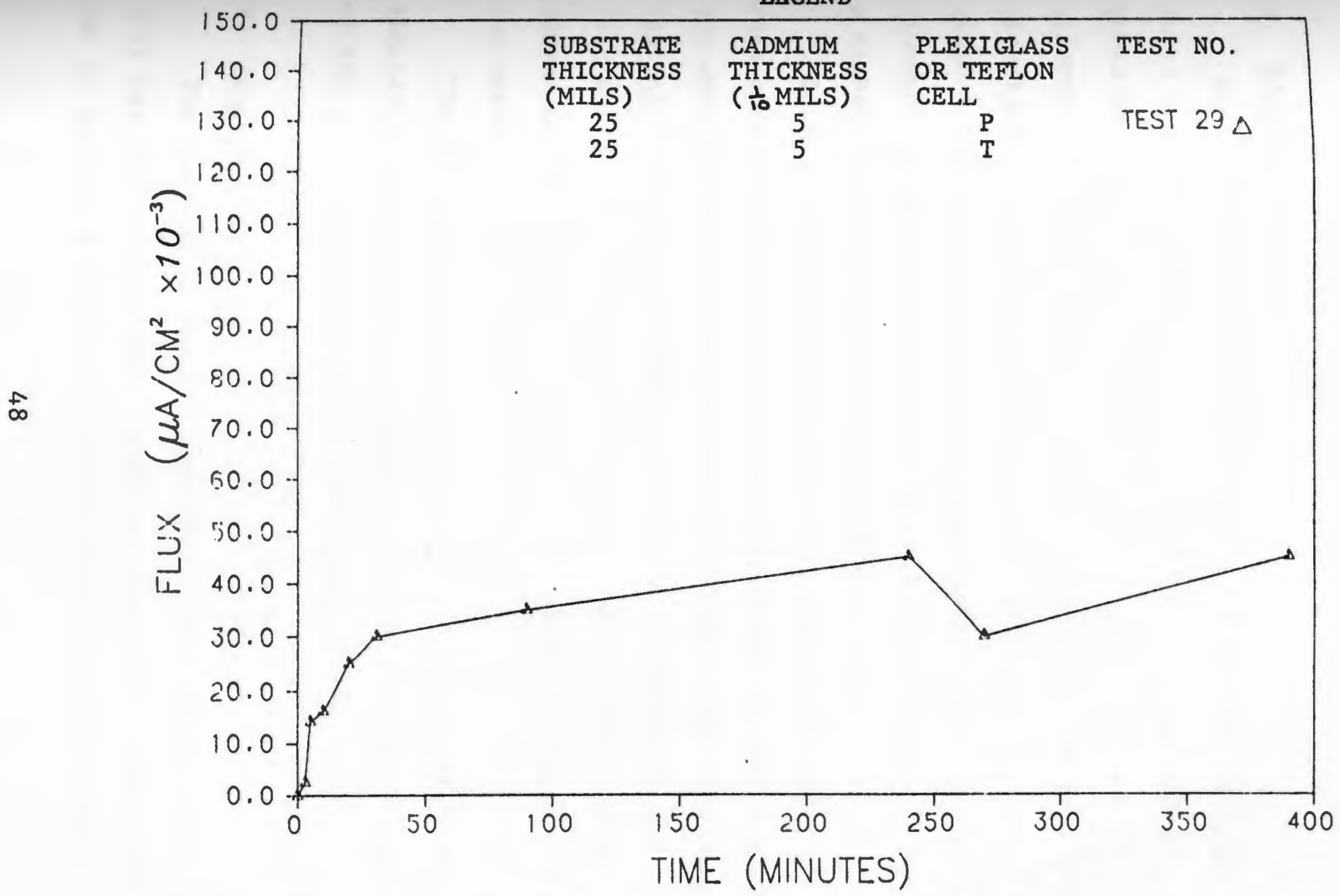

FIGURE 15. FLUX TRANSIENTS WITH 0.5 MILS CADMIUM ON 25 MILS IRON AT 0.5 MA CHARGING RATE 
CHAPTER 4

DISCUSSION

\section{A. Plating Comments}

At the beginning of the project, it was not anticipated that the majority of the research time and effort would be spent on the plating solution and technique development and refinement. The final plating solutions and techniques developed for this project successfully provided a methodology to run the experiments. Further refinement of the solutions and a technqiues would make for a higher percentage of useable samples.

Appendix I shows photos that are typical of the surface appearance of the inlet and exit sides of the exposed and unexposed areas of a permeation sample. The palladium coating displays its surface integrity on the inlet and exit surface on the unexposed sample. Only minute areas appear on the coating and those could either be voids or non-metalic impurities in the coating.

The exposed surfaces, both inlet and exit, are very similar to the unexposed surfaces and confirm the integrity of the palladium layer after completion of the test.

\section{B. Iron Samples}

The purpose of exposing uncoated iron samples with only palladium protective layers was two fold. The first was to confirm a proper and acceptable condition of the 
test equipment and experimental technique. The second was to establish a reference point for comparisons of permeation rates with coated samples.

The absorption transient curves presented in Figure 9 are hydrogen ionization fluxes through replicate samples of palladium coated iron and have a shape similar to those of earlier investigators. The breakthrough time is short but otherwise the repeatability and build shape are as expected. These curves are only used to confirm the proper functioning of the test equipment and are not used as the reference data.

The data presented in Figure 10 again confirms the proper equipment and technique functioning; these runs are the reference points for comparing with the coated samples. These runs very closely replicate those of Jones (24) data of a similar substrate thickness and hydrogen charing rate.

The ionization current fluxes in Figure 10 never reached a steady state after 80 hours of exposure. This effect was observed by others (24) and is speculated to be caused by internal damage in the iron substrate. This effect causes the creation of progressively larger free paths of diffusion through the substrate and therefore accounts for the steadily increasing ionization fluxes.

\section{Cadmium Effects}

The first group of samples tested with a cadmium 
coating were those run to determine the effects of the iron substrate base thickness. Figure 16 is a composite of all tests with a cadmium coating thickness of 0.2 mils. It shows a large scatter of steady state rates that do not appear to be dependent upon the iron substrate thickness. This lack of rate dependence is reasonable since the cadmium layer should be the rate determining step in the diffusion process.

Comparison of the 0.2 and 0.5 mil cadmium plating thickness sample rates, Figures $14 \& 15$ respectively, shows that the cadmium is the rate determining step. Figure 17 has the inverse thickness versus the steady state rate for the samples tested in the teflon cell and shows the expected inverse thickness dependence.

Comparison of the steady state flux rates of the samples without and with cadmium, Figures 9 and 16 respectively, show that the presence of the cadmium has dropped the flux rates by three orders of magnitude, therefore the cadmium is the rate controlling step. Hydrogen transport is a diffusion process and Figure 18 shows the expected diffusion concentrations gradients through the sample thickness (48).

From this data, comparisons now can be made with other coatings to determine their relative effectiveness of preventing hydrogen permeation through the various coatings. 


\section{LEGEND}

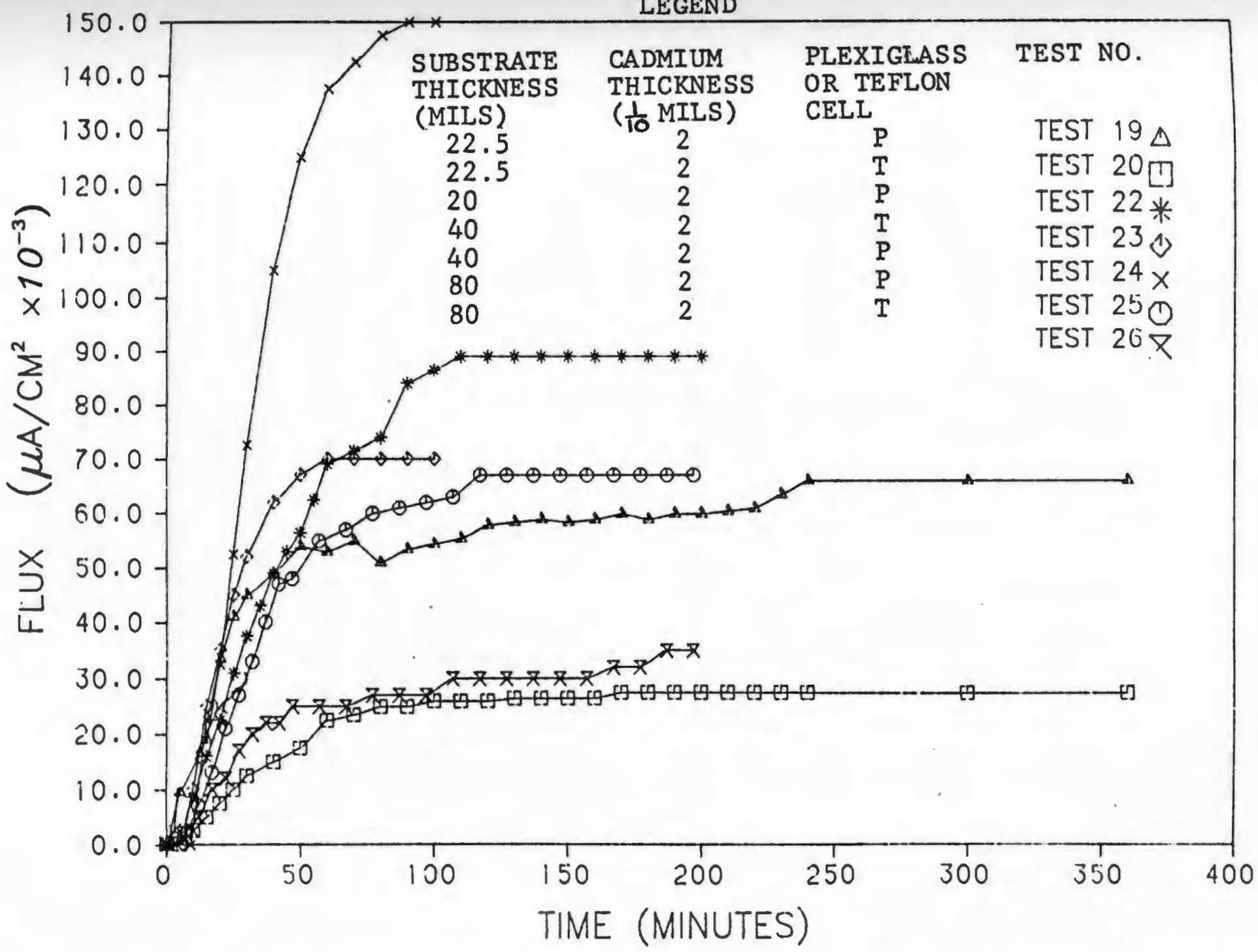

FIGURE 16. COMPOSITE OF ALL FLUX TRANSIENTS WITH 0.2 MILS CADMIUM AT 0.5 MA CHARGING RATE 


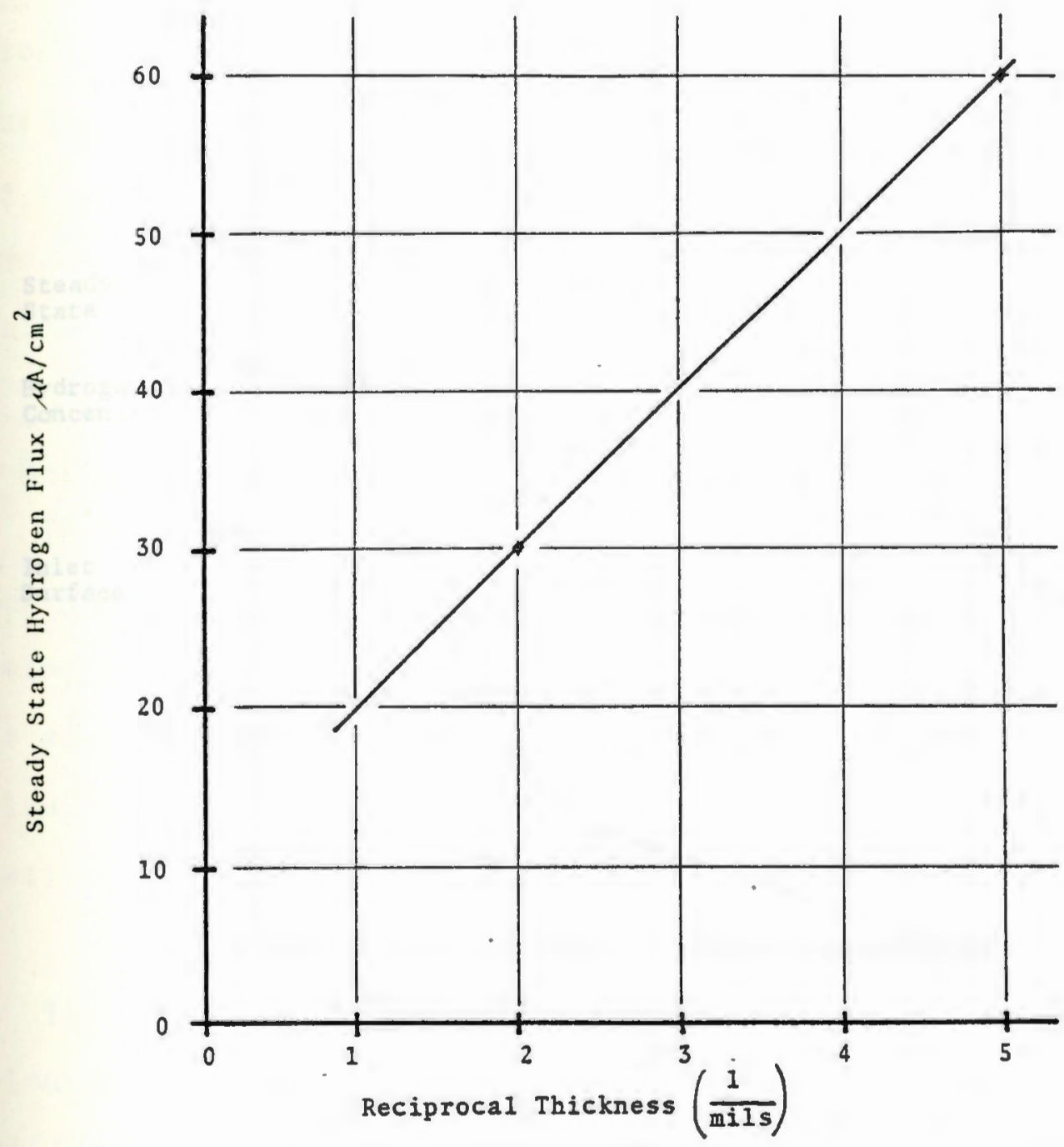

FIGURE 17. INVERSE THICXNESS VERSUS STEADY STATE FLUX FOR CADMIUM COATED SAMPLES 


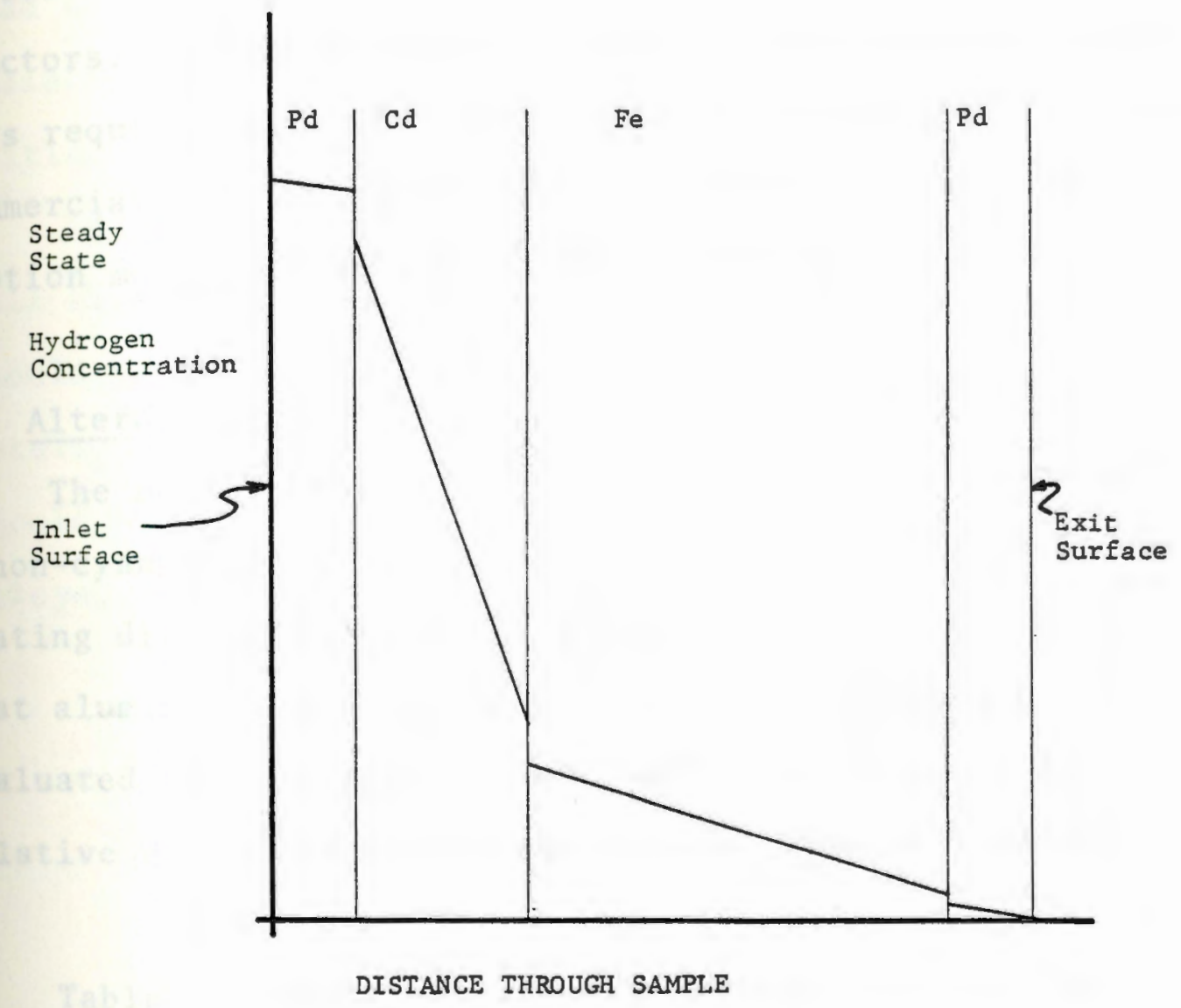

FIGURE 18. STEADY STATE HYDROGEN CONCENTRATION THROUGH CADMIUM PLATED SAMPLE 


\section{CHAPTER 5}

\section{RECOMMENDATIONS FOR FUTURE WORK}

\section{A. Plating Suggestions}

It is recommended that the future researchers have the various coatings electroplated by qualified outside contractors. The complexity and quality of composite coat. ings required for this research is higher than the average commercial shop is accustomed to producing, therefore discretion must be exercised in selecting the shop.

\section{B. Alternative Coatings}

The most likely commercial alternative to cadmium is a non-cyanide zinc. Aluminum has a good potential if the plating difficulties can be overcome. It is recommended that aluminum and both cyanide and non-cyanide $z$ inc be evaluated and compared to cadmium for determining the relative effectiveness of the various barrier coatings.

Table VII lists the lattice descriptions for the various metals used in this project and the metals under consideration as alternative coatings. The lattice description involved the metalic structure, its atomic radius, lattice parameters, and the interetched hole size from the $(000)$ direction. From this table and using a hydrogen atom size as $0.74 \AA$ (49), it is obvious that hydrogen can rapidly diffuse through palladium. The iron 
hole is smaller than the palladium hole yet larger than hydrogen atom. Cadmium has an interstitial hole size of $0.46 \mathrm{~A}$ which can explain why it is such an effective hydrogen barrier. Of the alternate metals under consideration, zinc has an interstitial hole size slightly larger than cadmium and should perform quite well and when a palladium plating process is developed. If the interstitial holes size analysis is valid.

Conversely, the aluminum and nickel interstitial hole sizes are substantially larger than hydrogen and should not prove to be effective hydrogen barriers as pure metals. Doping could fill the interstitial sites and should therefore be tested as pure and doped metals and alloys. 
TABLE VII

\section{INTERSTITIAL HOLE SIZES FOR VARIOUS METALS}

Lattice Description Metal

Structure

Atomic Radii ( $(\AA)$

Lattice Paramets $(\AA)$

ज
$\operatorname{Pd}$

$\mathrm{Fe}$

Cd

$\mathrm{Zn}$

A1

$\mathrm{Ni}$

FCC BCC HCP HCP FCC FCC

$\begin{array}{llllll}1.38 & 1.24 & 1.49 & 1.61 & 1.43 & 1.24\end{array}$

3.89

2. 86

$2.98 \times 3.23 \times 4.05$

3.52

(A)

Hole Shape

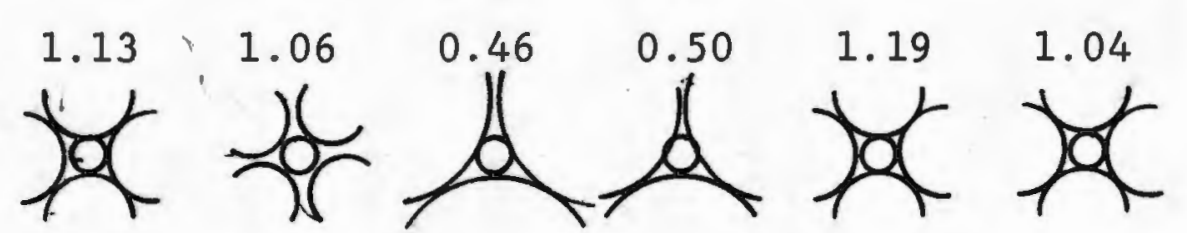


REFERENCES

1. H. Deville, and L. Troost, Compute Rendes, 57 (1853) 965, 977 (referenced in C. Kuehler, Ph.D. Dissertation, Princeton University, 1974).

2. I. Bernstein, and A. Thompson, ed., Hydrogen in Metals, American Society of Metals, Metals Park, OH, 1974.

3. A. Thompson and I Bernstein, eds., Effect of Hydrogen on Behavior of Materials, Proceedings of an International Conference, Moran, Wyoming, September, 1975.

4. Harris and Farr, eds., Hydrogen in Metals, Proceedings of the Meeting at Birmingham ux., Elsevier Sequola, 1976 .

5. C. Beachem, ed., Hydrogen Damage, American Society of Metals, 1977.

6. C. Zapffee, and C. Sims, Trans. A.I.M.E., 1941 Vol. 145, p 225-259.

7. C. Beachem, in Ref. 5, Introduction.

8. M. Loutham, and McNitt, in Ref. 3, p. 496.

9. R. Latanison, 0. Gastine, and C. Compeau, "Stress Corrosion Cracking and Hydrogen Embrittlement:

Differences and Similarities," Massachusetts Institute of Technology, Department of Materials Science and Engineering, January, 1978.

10. C. Zapffee and C. Sims, Trans. Aire., Vol. 145, 1941

11. A. Troiano, Trans. A.S.M., 1960, vol. 52, p. 54-80.

12. R. Oriani, Ber. Bunsenges Phys. Chem., 1972, vol. 76, p. 848-857.

13. N. Petch and P. Stables, Nature, 1952, vol. 169, p. 842-843.

14. C. Beachem, Met. Trans., 1972, vol. 3, p. 437-451.

15. D. Westlake, Trans. A.S.M., 1969, vol. 62, p. 10001006 . 
16. P. Bastien, and P. Azou, Proceedings First World Metals Congress, A.S.M., Cleveland, OH, 1951.

17. R. McCright, Ph.D. Thesis, Ohio State University, 1974 .

18. H. Tardif, and M. Marquis, Can. Met. Quar, 1962 Vol. I p. 153

19. S. Chatterjee, B. Atyea, and H. Pickering, Met. Trans, vo1. 9A, 1978, p. 389-395.

20. A. Atrens, D. Mezzanotte, N. Fiore, M. Genshaw, "Electrochemical Studies of Hydrogen Diffusion and Permeability in Nickel," Department of Metallurgical Engineering and Materials Science, University of Natre Dame, 1979 .

21. S. Venkatesan, R. Subramarian, M. Devanathan, Metal Finishing, May, 1966, p. 50.

22. Federal Specification QQ-P416C, Plating, Cadmium (Electrodeposited), January 29, 1971. Also see Military Specification MIL-C-8837A, Coating (Vacuum Deposited), 8 December 1969.

23. H. Townsend, Jr., Hydrogen in Metals, Conference, American Society of Metals, 1973.

24. J. Jones, University of Rhode Island, unpublished data.

25. C. Huffine, and J. Williams, Corrosion, Vol. 16, 1960, p. 102 .

26. W. Perkins, in Effects of Hydrogen on Behavior of Materials, 1975, p. 355.

27. J. Sherlock, and L. Shreir, Corrosion Science, Vol. 10, 1970, p. 561-569.

28. J. Sherlock, and L. Shreir, Corrosion Science, Vol. 11, 1971, p. 543-551.

29. A. Cook, "Unique Characteristics of Cadmium Electroplating," presented at Alternatives to Cadmium Electroplating in Metal Finishing, National Bureau of Standards, Gaithersburg, MD, Oct. 4-6, 1977.

30. "Government Industry Workshop on Alternatives for Cadmium Electroplating in Metal Finishing," National Bureau of Standards, Gaithersburg, MD, October 4-6, 1977. 
31. H. Rohrig, and R. Hecker, Thin Solid Films, Vol. 45, 1977 , p. 247-255.

32. M. Fontana, and N. Green, Corrosion Engineering, McGraw Hill, New York, 1971.

33. R. Wanhill \& P. deRijk, "Hydrogen Embrittlement of 4340 Steel by Cadmium Electroplating: Interim Report

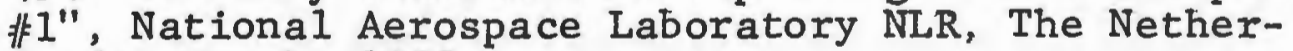
lands, March, 1973.

34. J. Hoffner, Solid Cadmium Embrittlement of 4340 Steel, N.A.D.C., Warminster, PA, 27 Jan. 1974.

35. V. Zhitenev, et al, Zashchita Metallov, Vol. 10, No. 4, p 462, July 1974.

36. W. Kerfoot, and S. Jacobs, "Cadmium Accrual in Combined Wastewater Treatment-Aqua Culture System," Environmental Science and Technology, Vol. 10, 1976, p. 662 .

37. Friberg, Nordberg, and Vouk, Handbook of Toxicity of Metals, Elsevier/North Holland Biomedical Press, NY, NY, 1980 .

38. H. Davis, and J. Gray, Trans. Inst. Met. Fin., Vol. 46, 1968, p. 12 .

39. L. Serota, Cadmium Embrittlement, Metal Finishing, May, 1965. p. 76-80.

40. P. Fischer and J. Jankowski, Naval Air Development Center, Report NADC 72045-VT, Warminster, PA, May 12, 1972 .

41. R. Heidersbach, J. Jones, and M. Surkein, "An Improved Electropermeation Technique for Studying Hydrogen Transport in Metals," Paper 4A3, Proceedings Second International Congress on Hydrogen in Metals, Paris, June 1977.

42. M. Devanathan and Z. Stachurski, Proceedings of the Royal Society, A27G, 1962.

43. M. Surkein, M.S. Thesis, Univ. Rhode Island, 1979.

44. J. Jones,- R. Heidersbach, M. Surkein, "Hydrogen Permeation of High Strength Steels," Offshore Technology Conference Paper Number 2801, 1977.

45. Guidebook \& Directory, Metal Finishing; Metals \& Plastics Publications Co., Inc., 1978. 
46. Alumatec, Inc. Oxnard, CA, Technical Literature.

47. Buehler Ultramet Sonic Cleaning Solution, Beuhler, LTD., Evanston, IL 60204.

48. J. Crank, "The Mathematics of Diffusion", Clarendon Press, Oxford, 1975.

49. B. Mahan, University Chemistry, Addison Wesley Publishing Co., 1969. 


\section{APPENDICES}

APPENDIX I PHOTOGRAPHS

APPENDIX II PALLASPEED TECHNICAL DATA

APPENDIX III HULL CELL INFORMATION

APPENDIX IV CADMIUM COMPOSITION ANALYSIS TECHNIQUES

APPENDIX $V$ CADMIUM LIQUID BRIGHTENER SPECIFICATIONS

APPENDIX VI ELECTROPLATING MASKING TAPE SPECIFICATIONS

APPENDIX VII ELECTROPLATING CALCULATIONS 


\section{APPENDIX I}

ELECTRON MICROSCOPE PHOTOGRAPHS 


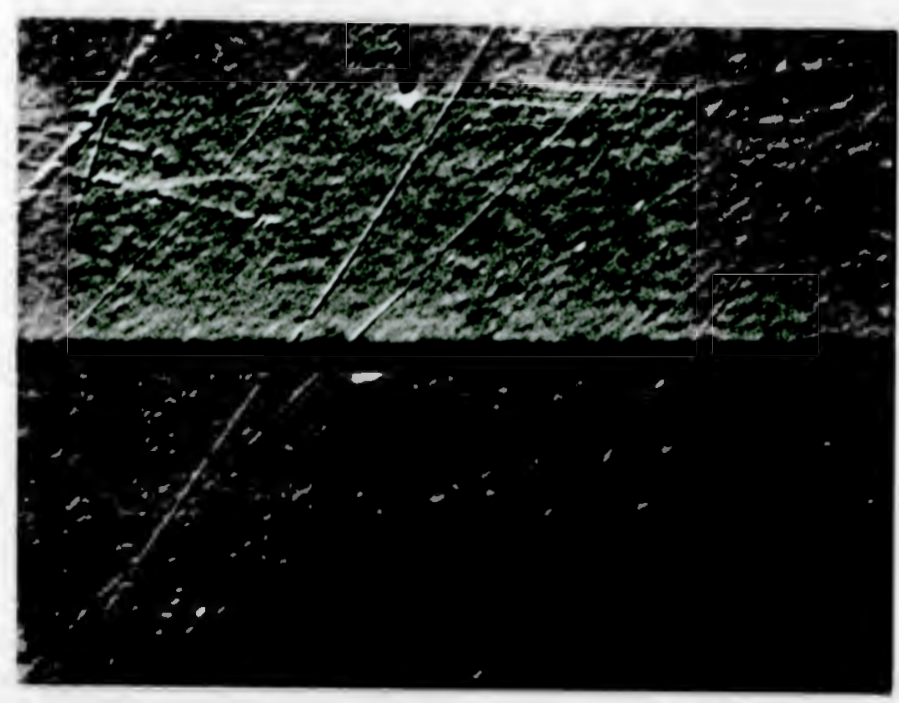

'INIET SIDE EXFOSED SURFACE(1000X)

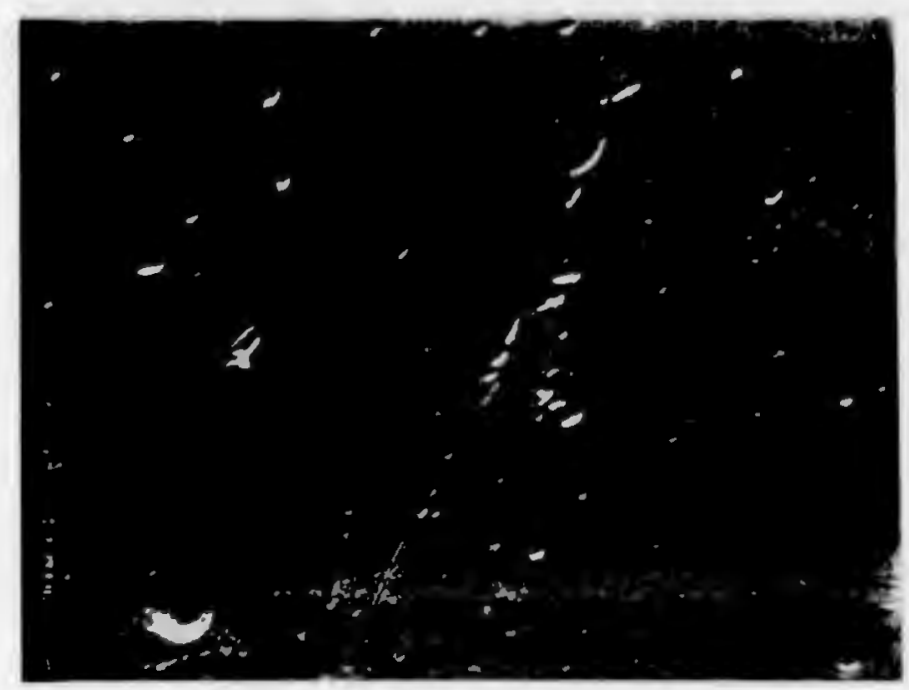

EXIT SIDE EXPOSED SURFICE (1000X)

P1cure 1. Typloal electron m1croscope photographs of inlet and exit sides of exposed surfaces. 


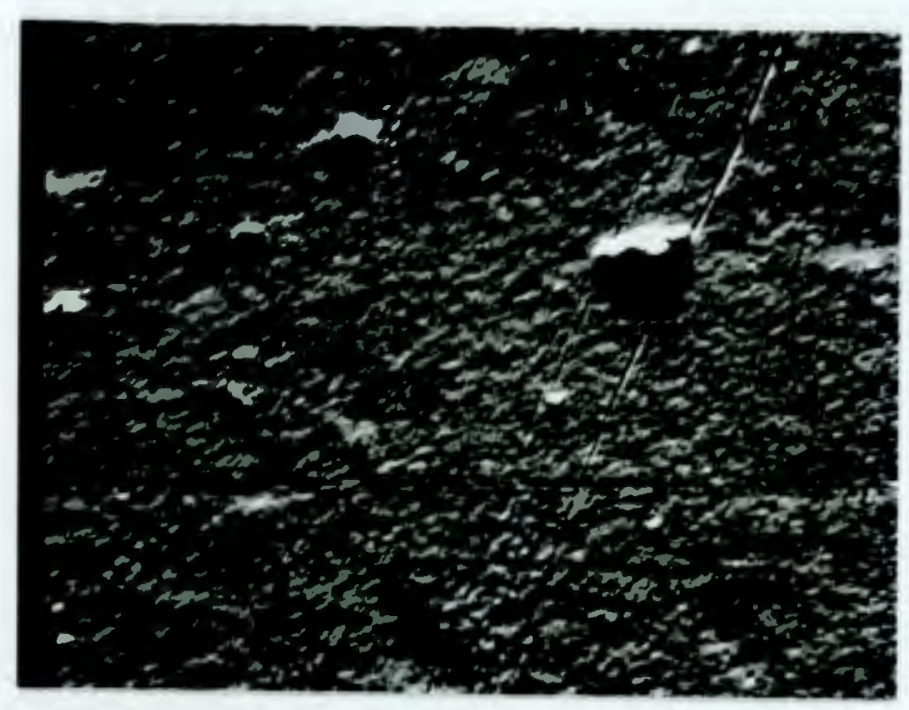

INLET SIDE UNEXPOSED SURFACE (1000X)

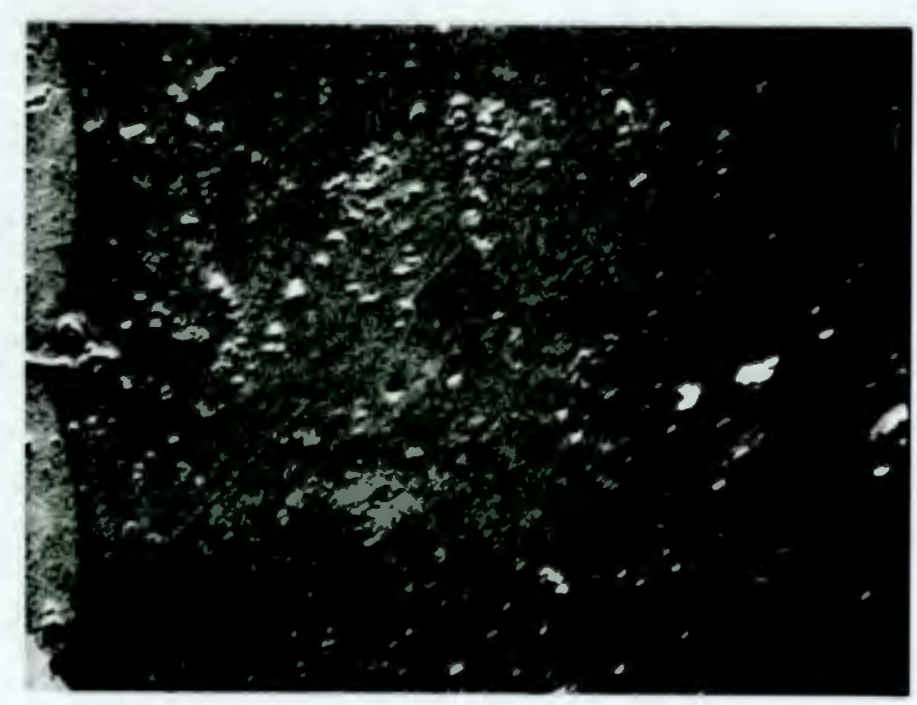

\section{EXIT SIDE UNEXPOSED SURFACE (1000X)}

F1cure 2. Typloal electron microscope photographs of inlet and exit sldes of unexposed surfaces. 
APPENDIX II

PALLASPEED TECHNICAL DATA 


\section{PALLASPEED}

PALLASPEED is an organically-brightened high speed palladium ath which is capable of operating over a temperature range from oom ambient to over $130^{\circ} \mathrm{F}$. The deposits are bright, highly ducjle, and exceptionally tarnish-resistant.

AKEUP:

PALLASPEED Makeup \#1

Palladium as PALLASPEED concentrate
1 gallon

1 pound

$10-60 \mathrm{gm}$.
100 gallons

100 pounds

$1000-6000 \mathrm{gm}$.

PERATING CONDITIONS:

$\mathrm{pH}$

Temperature

Anodes

Current Density

Specific Gravity

Agitation $-\quad 5.5-6.5$

-- Room - $130^{\circ} \mathrm{F}$. (see notes)

-- Platinized. Anode-to-cathode area ratio should be at least $1: 1$

-- see notes

-- $12^{\circ}$ Baume' minimum

-- Recommended

EPLENISHMENT and MAINTENANCE:

The current efficiency of this bath is in the range of 70-808 $t$ room temperature, and $85-958$ at $120^{\circ} \mathrm{F}$. At an efficiency of 908 , eplenish $36 \mathrm{ml}$ PALLASPEED concentrate-( 1.8 grams palladium metal) er ampere-hour. pH should be maintained at 5.5 - 6.5. pH may be djusted upwards if necessary with potassium hydroxide, or downards with phosphoric acid. Specific gravity may be increased by dding monopotassium phosphate. Under ordinary conditions, the rightening agent in this bath is self-maintaining.

\section{PERATING NOTES:}

At a concentration of 30 grams palladium per gallon, the workng range of this bath is from 1 to approximately 25ASF at room emperature; from 1 to approximately $40 \mathrm{ASF}$ at $120^{\circ} \mathrm{F}$. Deposit ightness is greatest at the lower operating temperatures. At ${ }^{\circ} \mathrm{F}$, the deposit will hold mirror-brightness when plated to thickesses exceeding one mil. Throwing power at low current densities 
$s$ also greatest at low temperatures. For barrel work, a temperaure of $80-90^{\circ} \mathrm{F}$ is recommended. Deposit ductility increases ith ifcreasing bath temperature. Knoop hardness of the deposit $s$ in the range of $200-220$ at room temperature, and in the range $140-160$ at $120^{\circ} \mathrm{F}$. For engineering purposes, a temperature of bout $120^{\circ} \mathrm{F}$ represents an optimum compromise of deposit brightness nd plating speed.

This bath when first installed undergoes a brief period of working-in" during which the bath color will change from very pale o a bright yellow, and the deposits will increase in brilliance, articularly at high current densities. During the working-in eriod it is best not to exceed a current density of about 10 ASF then the bath is being operated at $120^{\circ} \mathrm{F}$. When the bath is fully orked-in, a hull cell panel plated at 1 ampere for 2 minutes at $20^{\circ} \mathrm{F}$ should be bright and haze-free to an indicated current denity of about $40 \mathrm{ASF}$. Note: The development of a dark amber or rownish coloration in the bath indicates an excessive buildup of rganics which tend to reduce the current efficiency. In order to revent this the bath should be periodically carbon-treated or arbon-filtered. 
APPENDIX III

HULL CELL INFORMATION 


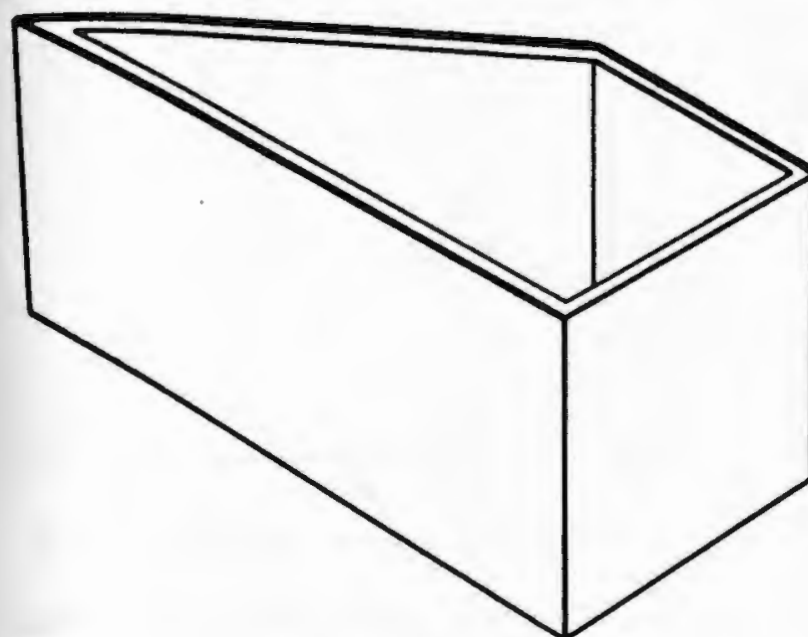

Fig. 1. Hull Cell.

A PLATING bath will operate successfully only when all sources of trouble are under proper control. This is an obvious fact, but the sources of trouble are not always obvious. Troubles may arise from improper chemical concentrations, drag-in of impurities, contamination from the atmosphere, contami. nation from the plating racks, products of decomposition of the chemicals in the bath, impurities in the water, or impurities from the anodes and chemicals themselves.

A number of foreign metals may enter the bath from several sources. If these metals are more electronegative than the metal being deposited they will cause trouble after they reach a critical concentration. Undesirable organic material may enter the bath from rack coatings, stop-offs, or by decomposition of addition agents.

There is one method to test for these and other trou. bles that produce an undesirable appearing plate. The way to do this is to plate a few pieces of work and observe the results. These tests may indicate freedom from trouble but upon plating at another current density or plating an article of an entirely different shape, troubles may appear. Such troubles may be detected by plating a series of test specimens over a range of current densities.

If plating at several current densities reveals a troublesome plating range then it is logical to use a plating test that covers the entire plating range in one operation. The Hull cell was developed specifically to provide such a test. A plate from this test covers the normal plating range plus a higher and lower current density range. It is in this extra range particularily that troubles may be predicted before they appear in the normal plating range.

Let us take an example to show how the plating test reveals troubles:

A bright nickel bath begins to develop a smoky deposit on production pieces. Chemical analyses show that all essential chemicals, including the primary brightener, are within the proper limits. Sufficient anti-pit agent is known to be present by measurement of surface tension.

A plating test is run and the same smoky deposit appears over part of the plating range. From previous experience with prepared standards it is known that this typical test plate indicates an excessive amount

\section{The Hull Cell}

\author{
BY H. J. SEDUSKY and J. B. MOHLER
}

Research Chemists. The Cleveland Graphite Bronze Co.

of anti-pit agent present. The surface tension measurement did not locate the trouble because the surface tension test does not reveal an excessive amount of anti-pit agent, but only establishes that a sufficient amount is present.

The bath may now either be treated with activated carbon or electrolyzed with dummy cathodes to removc all or part of the surface active material. After treatment and readjustment of the bath a second test may be run to confirm expected bright plating.

The point to this hyopthetical case is that the best way to make an over-all test is by a plating test and the best plating test to use is one that covers the entire plating range required in production.

The Hull test is a universal plating range test. It may be used to predict results for the variation in current density on all but the most complicated shapes. The variation in current density during plating is the greatest of any of the common variables. It does not change at a given point with time but it does vary with the shape of the article being plated. It is low in recesses and high on corners and edges. Tempera. ture, voltage, chemical composition and agitation are not variable for the normal time used to plate one rack but the current density varies at almost every point on every piece. Usually, however, the current density stays within the allowable plating range.

A Hull test may be run and the results show that

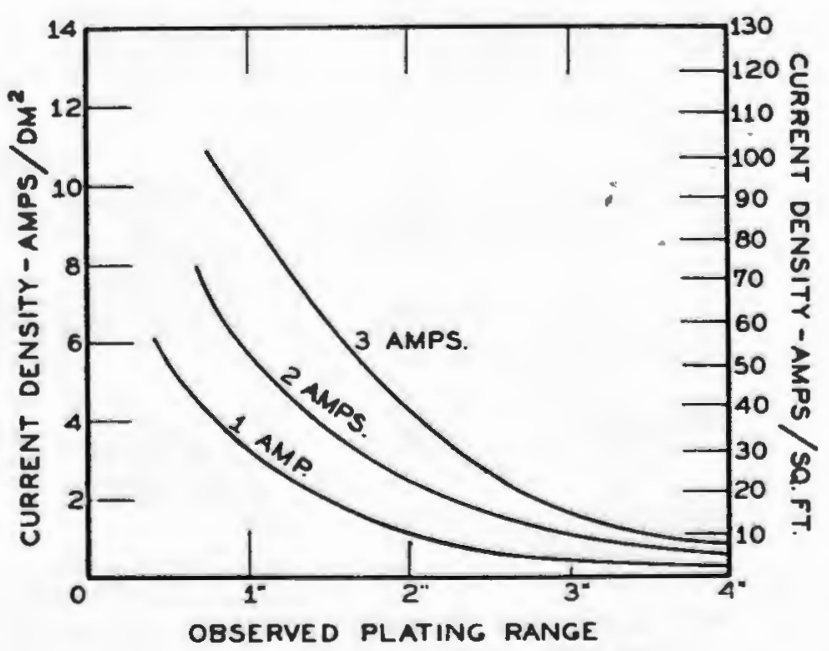

Fig. 2. Plating range of Hull Cell. 


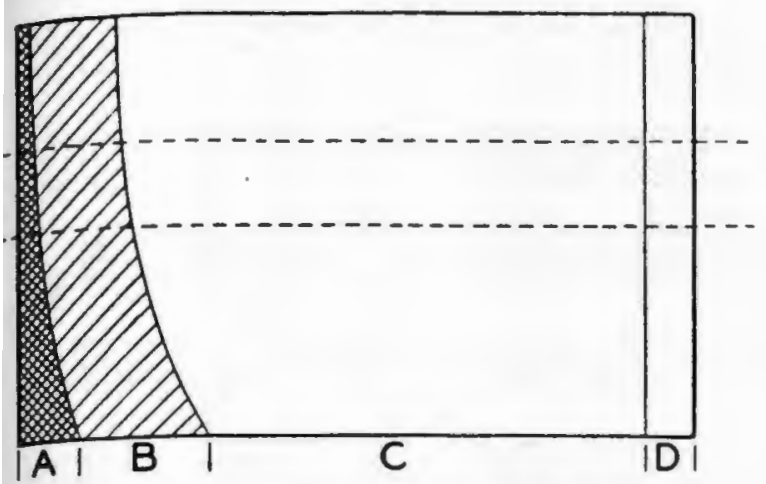

Fig. 3. Typical Hull test plote of a nickel bath.

e width of the plating range available is at an timum value. At the same time current density oubles may be experienced in the bath (such as burn$g$ in high current density areas). An attempt to overme this trouble may be made by lowering the total urrent used. The burning may cease but new diffuties may now be encountered by the pieces not vering in low current density areas. The plating st showed that the bath was functioning at its optium range. However, experience with the bath showed at the range was not wide enough for the pieces being ated. The problem then is one of racking and must solved by robbing, shadowing or anode arrange. ent. The plating test was of specific value in that it 1owed that attempts to change the bath and extend e plating range would be useless.

The Hull cell may be used to measure plating ranges ut its greatest value is as an analytical and control istrument. As such, it may be used both to detect resent troubles and avoid future difficulties.

It is possible to control a plating bath with nothing ore than a Hull cell and a hydrometer. A chromic cid bath is an example of a bath that may be control$d$ in this manner without chemical analyses. A bath complicated as the brass bath may also be controld to a great extent by the Hull test. For most baths owever, it is best to run both the plating test and hemical analyses since the latter gives definite, derable, quantitative information.

The cell used in the Hull test is shown in Figure 1. he cell is so constructed that the current density hanges regularly for every point along the width of se cathode.

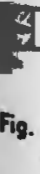

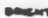

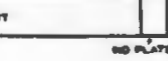

4. Notebook entry of - Hull test plate.

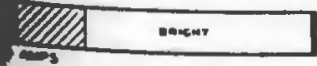

-men

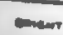

Fig. S. Effect of total car. rent on plating range.
The prelerred cell ${ }^{1}$ holds 267 milliliters of solution. For this volume, an addition of 2 grams of solid is equivalent to one ounce per gallon. An anode is placed at the square end of the cell so as to cover the entire end. A $2 \frac{1}{2} 2^{\prime \prime} \times 4^{\prime \prime}$ cathode is placed at the opposite inclined end of the cell.

The total current used depends on the type of bath being tested. The current density at any point on the cathode can be obtained by referring to the graph in Figure 2.

The graph of Figure 2 was calculated from the equation:

$$
\begin{aligned}
& \mathrm{A}=\mathrm{C}(27.7-48.7 \log \mathrm{L}) \\
& \text { Where } \mathrm{A}=\text { current density } \\
& \mathrm{C}=\text { total current } \\
& \mathrm{L}=\text { distance along cathode }
\end{aligned}
$$

This equation does not hold strictly true for all plating baths but the variation from bath to bath is not large. ${ }^{2}$ In any practical case it is advisable to run standard plates for all of the important bath variables
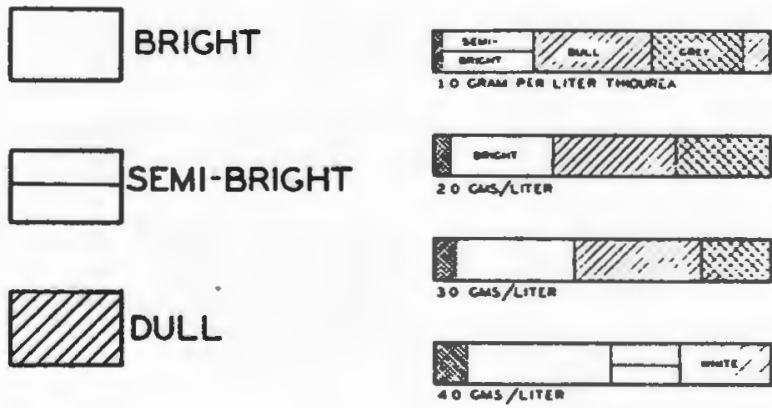
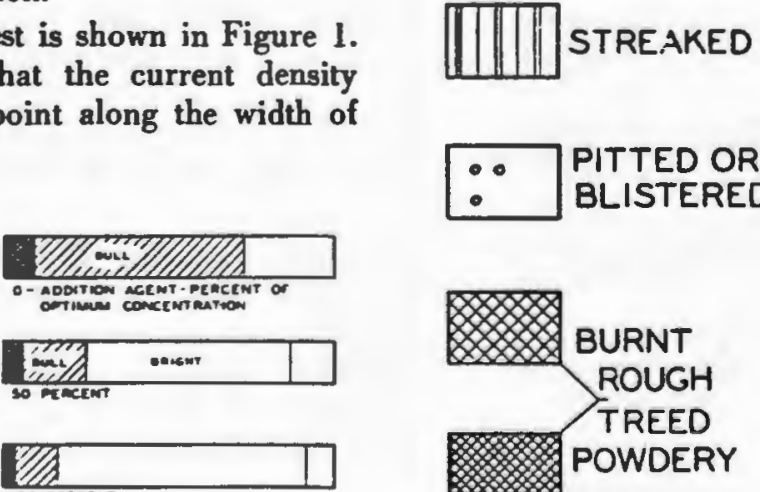

100 rincew
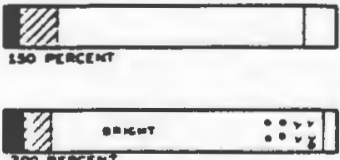

Fig. 6. Effect of addition ogent on a nickel both.

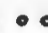

PITTED OR BLISTERED

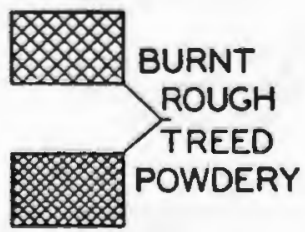

YYYYBRITTLE OR YYYYCRACKED

Fig. 8. Generol code, illustroting the common method of indicating appeorance of areas on test plates.

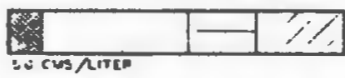

Fig. 9. The effect of on addition ogent on on ocid silver both. 1 amp., steel cothode, room temp.
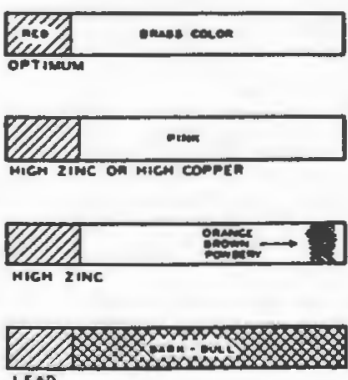

Fig. 10. Brass. 1 omp., steel cothode, room temp. 

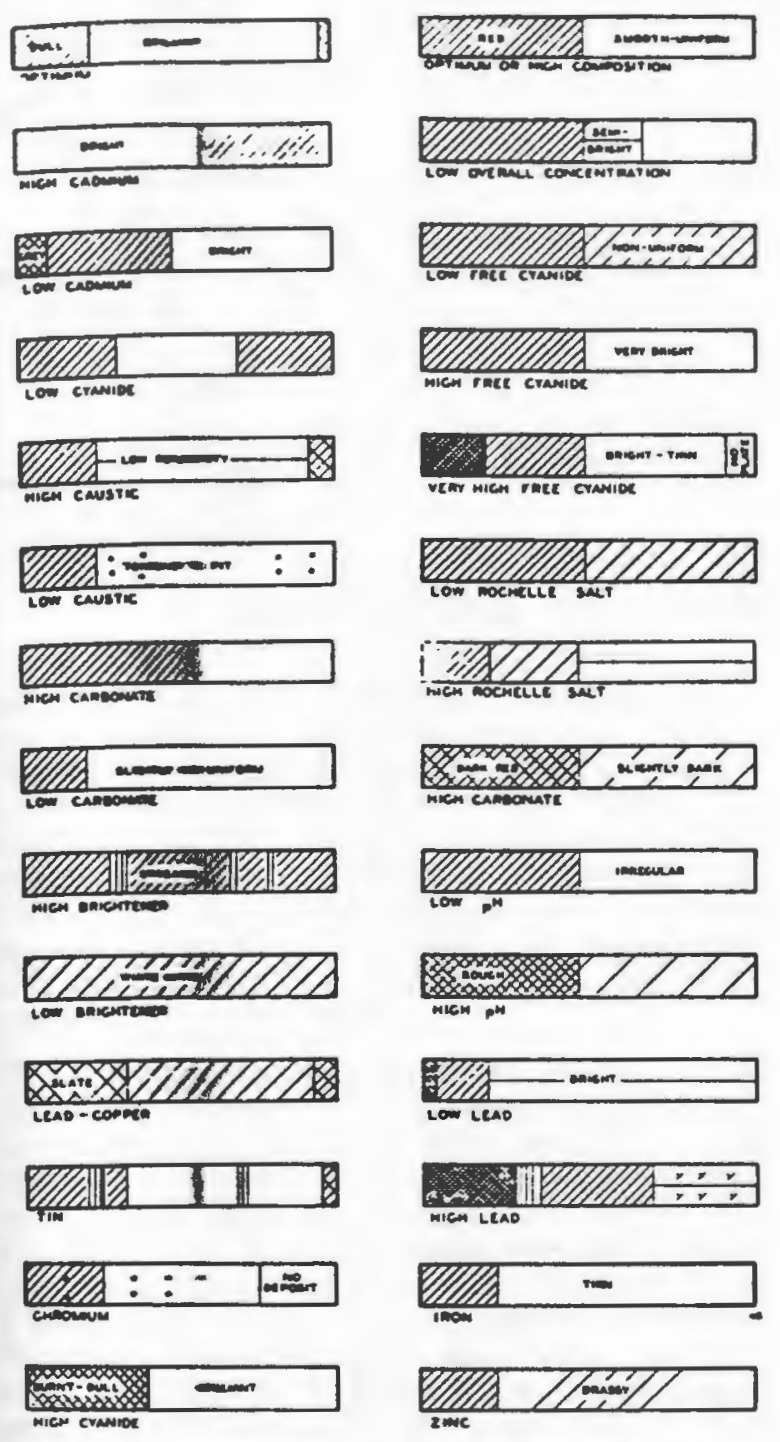

Fig. 11. contum. 3 omps., fresed steel cathode, temp.
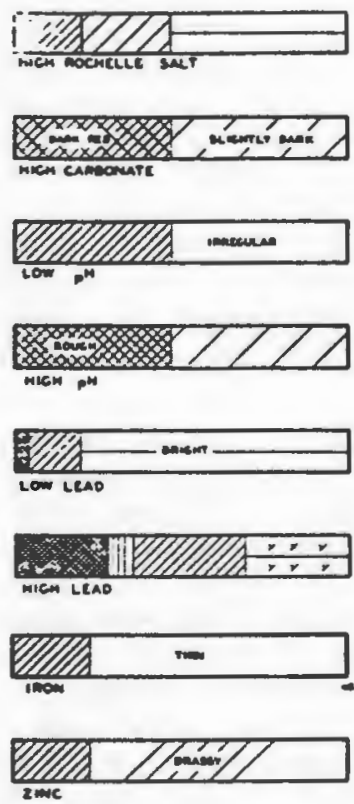

Fig. 12. Rochelle copper. 2 amps., steel cathode, temp. $50-60^{\circ} \mathrm{C}$.

in order to bome fainiliar with the typical appearance of a preparation of the standards should imulate as ch as possible production operations including dowing, pickling and striking steps in order to obtrinearimum information from the plates. If the bath is tated in actual practice, as in the case of the high cyancy cyande copper bath, then mild agitation with stirring rod should be used during the test.

It is not ans best to run the test at the same average operating dentent density since some other total quantity of cain may give greater sensitivity in seeking inform in on the effect of a definite addative. An example presently be given to illustrate this point but fint us look at a typical Hull cell plate in Figure 3.

A plate - Figure 3 might be obtained from a cold nickel Lilnoing a brightener. The high current dansity end at e plate is at the left. The area $A$ is derk and re is dull, $C$ is bright and at D there is no depoci $-i$ is very thin. The lines from the top to the botw of the plate marking the zones between $A$ and 3 ind between $B$ and $C$ curve toward the low curnasity end. This is caused by inter-

ruption of the flow of solution along the cathode Ly the bottom of the cell, but it does not interfere with interpretation of the results. A good scheme for showing typical results is to sketch the appearance of only the part of the plate observed between the dotted lines. A notebook entry would then appear as in Figure 4.

If the purpose of the test is to evaluate the effect of addition agent concentration in a new bath, the total current used should be that which will give the widest possible bright range. For instance, the plates shown in Figure 5 might be obtained for a total current of 1,2 and 3 amperes.

It is seen that as the total current is increased the

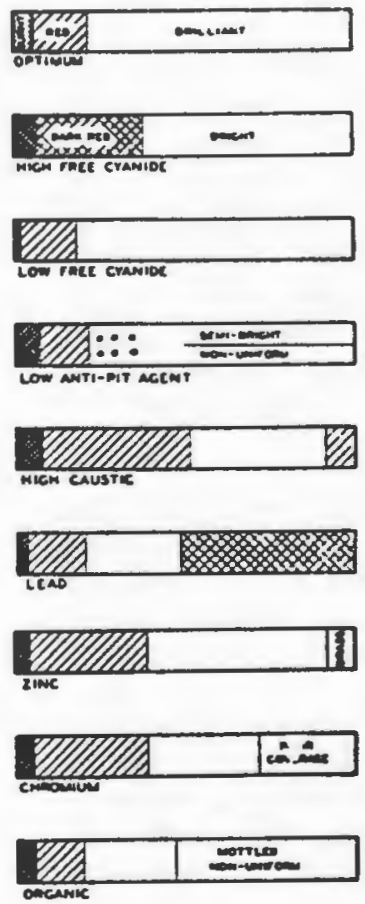

Fig. 13. High efficiency eopper. 2 omps., steel cathode, agitate length of cathode 4 inches per second, temp. $75-85^{\circ} \mathrm{C}$.
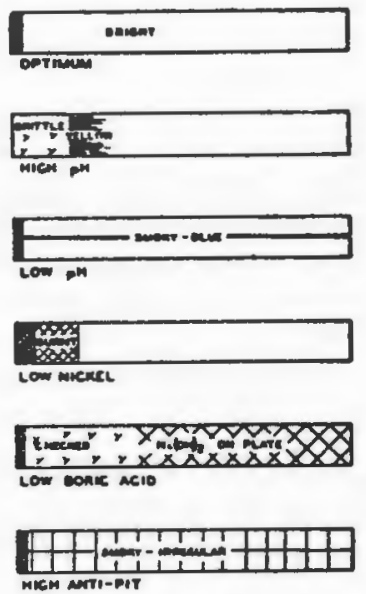

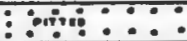

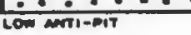
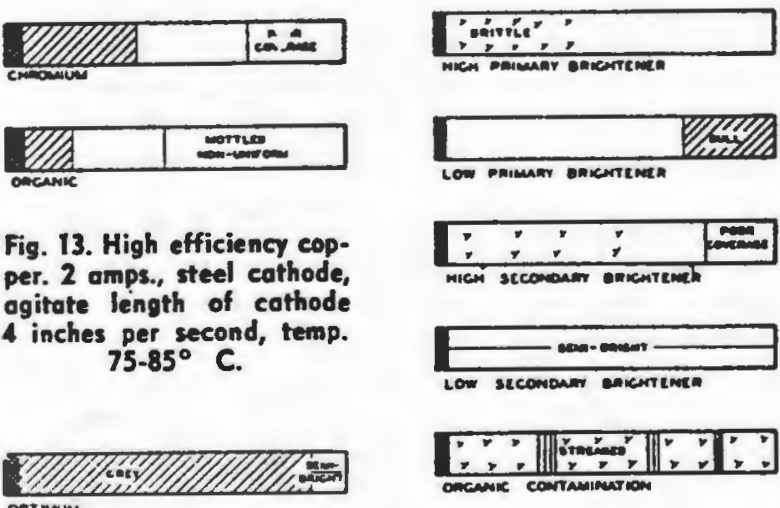
oncenic compamiousiom

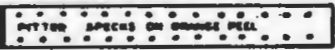

a

Los acor

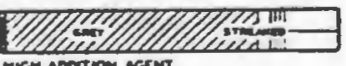

Fig. 14. Acid lead (fluoborute). 3 omps., steel cathode, room temp.

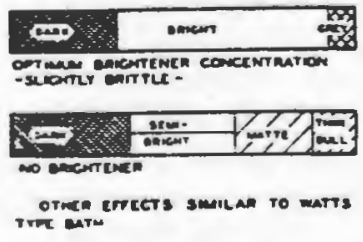

Fig. 15. Barrel nickel. 2 amps., steel cothode, room 


\section{TECHNICAL BULLETIN}

R. O. HULL \& COMPANY, INC., 3203 WEST 71 ST., CLEVELAND, OHIO 44102

\section{DIRECTIONS FOR HULL CELL PLATING TESTS}

The Hull Cell (U.S. Patent 2,149,344) is a miniature plating unit designed to produce a cathode deposit that records the character of electroplate obtained at all current densities within the operating range. The character of deposit so made is dependent upon the condition of the plating bath with respect to the primary components, addition agents, and impurities. The Hull Cell enables the experienced operator to determine the following facts regarding plating baths:

The approximate limits of bright density range. This is accomplished by comparison of bright plated areas on the panel with the current densities given in the chart. Thus, if the bright or operable range is between $11 / 4$ inches and $21 / 2$ inches as measured from the left side of the plate, and the total current applied is 3 amps., the corresponding respective current densities from the curve are 70 amps./sq. $\mathrm{ft}$. and $25 \mathrm{amps} . / \mathrm{sq}$. $\mathrm{ft}$. Since these values represent extreme limits, it does not follow that either of these current densities can be used in a plating bath without obtaining poor areas of deposit, but some intermediate current density such as 50 amps./sq. ft. should work best. As a general rule, the acid or non-cyanide baths should show bright or otherwise acceptable ranges from the low to high current density end of the plate over at least three-fourths of the cathode plate, alkaline or cyanide baths over at least one-half of the cathode plate, and baths for barrel plating over at least the lower one-third of the plate.

2. The approximate concentrations of the primary constitutents, such as cadmium content, so- dium cyanide content, nickel metal content, etc. Generally, the higher the metal content of a bath, the higher (but not necessarily wider) is the operable bright current density range. The voltage across the cell also indicates the bath composition, i.e., cyanide in cadmium, or impurities and trivalent chromium in chromium.

3. Addition agent concentration. Although a few addition agents can be determined by analysis, usually the Hull Cell provides the only satisfactory means for controlling the addition of these highly important materials, provided they exercise a visible effect upon deposits.

4. Metallic or organic impurities. Foreign metals or other harmful impurities in a plating bath exercise a definite effect on the appearance of the Hull Cell deposit, and their presence or absence can be established without difficulty.

5. The Hull Cell is also an indispensible instrument for experimental plating investigations such as addition agents, "covering power" or the lowest current density at which a deposit is produced, average cathode efficiency, average metal distribution or throwing power, and effects of $\mathrm{pH}$, temperature, and decomposition products. The clear lucite Hull Cell enables the operator to observe the plating on the back of the panel to determine relative covering power at very low current densities. Clear lucite also makes it possible to insure complete solution of additions.

\section{METHOD OF TEST}

Before making a Hull Cell plating test, the following points must be observed.

1. Bring the plating bath to be tested to operating level in the plating tank.

2. Either stir the bath thoroughly or use a sampling tube extending to the bottom of the tank, going over the tank uniformly from one end to the other.

3. Be sure that the sample to be tested is brought to and kept at the proper operating tempera- ture during the test. The best method for testing samples at high temperature is by use of the Model WT or HT Hull Cell, in which are incorporated provisions for heating element with thermostat control.

4. Use a clean Hull Cell and clean cathode. If more than one kind of plating bath is to be tested regularly, one cell should be used exclusively for each type of bath to avoid contamination of one bath by the other. 


\section{METHOD OF TEST (Continued)}

ce Hull Cell plating tests are not to be reded as eliminating the necessity for occaal chemical analysis, such analysis should made before the plating test so that the th sample can be adjusted to the optimum nposition either prior to or during the seence of Hull Cell tests.

zinc plated steel cathodes provided with set must be stripped of zinc by dipping in olution of half hydrochloric acid and half ter and cleaned with a wet, clean cloth or paper towel, just before use. Remember Hull Cell is an actual plating tank and properly prepared specimens will not reand satisfactorialy in the cell, just as in mmercial practice.

ating times in the Hull Cell should be timed actly for duplication of results. These times not all the same and are specified in the ction which follows for the different soluins. A convenient timer can be supplied as accessory to the Hull Cell Set.

proper volume of sample of plating bath $267 \mathrm{ml}$. for the $267 \mathrm{ml}$. Hull Cell, $534 \mathrm{ml}$. for e $534 \mathrm{ml}$. Hull Cell or $1000 \mathrm{ml}$. for the 1000 . Hull Cell. Two grams addition to $267 \mathrm{ml}$. grams addition to the $534 \mathrm{ml}$. or 7.5 grams tition to $1000 \mathrm{ml}$. Hull Cell is equal to one per gallon in the plating tank. To test bath sample hot, use the Model WT or HT
Hull Cell. Never put a lucite Hull Cell on a hotplate.

9. The Filtered Output Rectified Model B-267 for the $267 \mathrm{ml}$. Hull Cell or Model B-1000 for the $1000 \mathrm{ml}$. Hull Cell is the preferred current source. A single-phase rectified without a properly designed filter circuit must not be used. Two 6-volt storage batteries connected in series usually give sufficient voltage for the $267 \mathrm{ml}$. Hull Cell but this source is less convenient than the rectifier mentioned.

10. Steel cathodes have a semi-bright and uniform surface. Cathodes should be used once and filed for future reference and not stripped for re-use, to avoid destruction of the surface. Experience has shown that poor or non-uniform steel surfaces are very misleading in interpretation of results. Replacement cathodes are available upon order from us that duplicate the original zinc plated cathode plates provided with the set. Polished brass panels are also available for copper, nickel, and chrome plating tests.

11. Do not make too many tests on one sample of plating bath. Generally 6 to 8 plates can be made on a single nickel plating bath sample wnless the $\mathrm{pH}$ is checked after each plate. Here the H'T 534 is desirable because of the high volume-low current ratio.

12. For conversion - oz./gal: × $6.25=\mathrm{lb} . / 100 \mathrm{gal}$.

\section{SPECIFIC BATHS}

far the best means of using the Hull Cell test efficiently is first to determine and the effects of every variation in each type of bath used in production. Thus, if a bright bath is used, each constituent should be in tum, and effects noted on the cathode it, including nickel content, sulfate content, de content, brightening agents, and the probnetal impurities such as copper, lead, zinc, conducting such tests, it will be found very ageous to make up dilute solutions of on agents so that unit volumes added to the Cell volume of $267 \mathrm{ml}$. are equivalent to additions to the plating bath. Practically all bath concentrations are figured or stated in per gallon.
For solid chemicals the addition of 2 grams to $267 \mathrm{ml}$., 4 grams to $534 \mathrm{ml}$., and 7.5 grams to $1000 \mathrm{ml}$. Hull Cells are equivalent to one (1.0) ounce per gallon to the plating tank. Liquid chemicals such as brighteners or addition agents are normally specified or controlled on the basis of liquid ounces per gallon.

When the concentrated addition agent is a liquid, a diluted solution of the concentrate is recommended for Hull Cell additions and testing. The concentrate should be diluted to a $20 \%$ by volume solution. The addition of one $(1.0) \mathrm{ml}$. of a $20 \%$ (vol) solution to a 267 mi HuI equvalent to an addition of $0.1 \mathrm{fl}$ - ozelgallon of the concentrate to the plating tank. 
APPENDIX IV

CADMIUM COMPOSITION ANALYSIS TECHNIQUES 


\section{TECHNICAL BULLETIN}

R. O. HULL \& COMPANY, INC., 3203 WEST 7I ST., CLEVELAND, OHIO 44102

SPECIAL PURIFICATION PROCEDURES FOR CYANIDE CADMIUM PLATING SOLUTIONS

On frequent occasions, a cadmium bath may become contaminated with materials which can be removed or rendered Inert by simple additions to the bath of a sulfide or of hydrogen peroxide.

Many heavy metals, lead in particular, are precipitated with sulfide. In some cases a sulfide appears to tle-up or complex some contaminants. A normal full addition is one fluid ounce of a liquid sulfide such as Rohco Zinc Purtfier per 100 gallons of plating solution.

The need for sulfide is readily checked by an addition to the Hull Cell and this should be done prior to any addition to the tank. An overdose can preclpitate cadmium sulfide, which may necessitate a shut down and filtering.

Another useful purffying agent is 30 or $35 \%$ hydrogen peroxide. This can oxidize any tin contamination to a much less harmful form. It can also oxidize some organic materials to a less harmful form and may eliminate a carbon treatment.

A normal full addition is one quart per 100 gallons of plating solution. Th1s will normally cause considerable foaming of the tank, and will interfere with the normal metal distribution while it is working. It is recommended that peroxide additions be made prior to an over-night shut down or before a week-end. Some brightener may be lost by this treatment. A Hull Cell is a good way to determine the effectiveness of a peroxide treatment, and a panel should be run immediately after the addition and the next day. An immediate improvement is an Indication of tin. 


\section{How to make up a new bath}

For maximum plating speed, brightness, and economy, the cadmium plating bath should be made up and maintained at the proper chemical composition. The range of concentrations given below for the various bath constituents will serve as a guide for proper bath maintenance. Modifications in composifion may be desirable to meet special operating requirements, and the Enthonics Laboratory will be happy to make more specific recommendations.

\section{bath composition}

we recommend ...

\begin{tabular}{lcc} 
& sttll & barrel \\
cadmium metal & $2.2-3.75 \mathrm{oz} / \mathrm{gal}$. & $2.0-2.75 \mathrm{oz} / \mathrm{gal}$. \\
lotal sodium cyanide & $16.0-16.0 \mathrm{oz} . / \mathrm{gal}$. & $15.0-18.0 \mathrm{oz} / \mathrm{gal}$. \\
caustic soda & $1.5-3.0 \mathrm{oz} / \mathrm{gal}$. & $3.0-4.5 \mathrm{oz} / \mathrm{gal}$. \\
sodium carbonale & $2.0-6.0 \mathrm{oz} . / \mathrm{gal}$. & $2.0-6.0 \mathrm{oz} / \mathrm{gal}$. \\
Enthobrite brightener & \multicolumn{2}{c}{ as recommended }
\end{tabular}

CADMIUM METAL: The codmium content may vary quite widely as indicated obove particularly in a still both. For maximum throwing power, use the lowest cadmium content and the highest cyanide content recommended above. Far maximum plating speod, use the highest cadmium and sodium cyanide contents recommended abave. The maximum allawable current density varies with the cadmium content as fallaws:

$\begin{array}{cc}\text { cadmium } & \text { max. current density } \\ \text { (ox./gal.) } & 20 \\ 2.2 & 25 \\ 2.75 & 45 \\ 3.25 & 60 \\ 3.75 & \end{array}$

SODIUM CYANIDE: The sodium cyanide content is related to the codmium content as indicated above under "Cadmium Motal." Aso, at high both temperatures o higher cyanide cantent will give more uniform resulis.

CAUSTIC SODA: The caustic soda content is very important to bath stability and performance. When additions are required, os determined by analysis, they should be made of the rote of no more thon 0.5 ox./gal. per 16 hours of operation.

SODIUM CARBONATE: The sodium carbonole content builds up slowly in a codmium ploting bath due to decomposition of sodium cronide. Above 8 oz./gal. it limits the maximum current density which con be used without "burning." Sodium carbonate con be removed by freexing it out at $25-30^{\circ} \mathrm{F}$ ond deconting the clear solution.

\section{OPERATING CONDITIONS:}

\begin{tabular}{lll} 
& \multicolumn{1}{c}{ still } & \multicolumn{1}{c}{ barrel } \\
temperature & $75-105^{\circ} \mathrm{F}$ & $75-95^{\circ} \mathrm{F}$ \\
current density & $5-70 \mathrm{amps} / \mathrm{sq} . \mathrm{ff}$. & $3-10 \mathrm{omps} / \mathrm{sq} . \mathrm{ft}$. \\
volts & $3-6$ & $9-15$
\end{tabular}

\section{new solution}

to prepare...

a new cadmium plating bath, the following chemicals are required for each 100 gallons of solution:

\begin{tabular}{lcr} 
& still & barrel \\
cadmium oxide & 20 lbs. & 17 lbs. \\
sodium oyanide & 112 lbs. & 110 lbs. \\
caustic soda & & 8 lbs. \\
Enthobrite brightener & \multicolumn{2}{c}{ as recommended }
\end{tabular}

These amounts will give bath compositions approximately in the middle of the ranges listed under "Bath Composition."

MAKE-UP PROCEDURE:

1. Fill tank $1 / 2$ to $4 / 3$ full af water at room temperature.

2. Add the sodium cyanide, stirring until dissolved.

3. Make a slumy of the cadmium oxide in plain water contained in a separate pail or drum.

4. Stowly add the slumy of cadmium oxide to the tank while stiming. Continue lo stir until all the cadmium oxide has dissolved.

5. (For borret plating only) Add the caustic soda, stirring until dissolved.

6. Add the required amount of the appropriate Enthobrite brightener.

7. Bring the both volume up to operating level with cold water.

8. Plating may be started at this time providing the lemperature of the both is nol over $95^{\circ} \mathrm{F}$.

NOTE: A flocculent precipitate may be formed in moking up the bath and is due to the hordness of the waler. This precipitate is not detrimental in borrel plating, but moy cause femporary roughness in still plating. If may be removed by Altrotion.

ENTHOBRITE CADMIUM CONCENTRATE - a more convenient way to make up a new cadmium plating both is ta use Enthobrite Cadmium Concentrate, a purifed and flterad cancentroted cadmium solution containing opproximately ten times the amount of cadmium required per gallon in a plating bath. Eliminates the need for dissolving codmium oxide. Dato sheets ore available from Enthone.

- Coustic sodo is formed when cadmium oxide is added to sodium cranide, and no additional coustic soda is required to make up a still both. Additional caustic soda is added to barrel boths to give higher conductivity and maximum productivity. 
APPENDIX V

CADMIUM LIQUID BRIGHTENER SPECIFICATIONS 


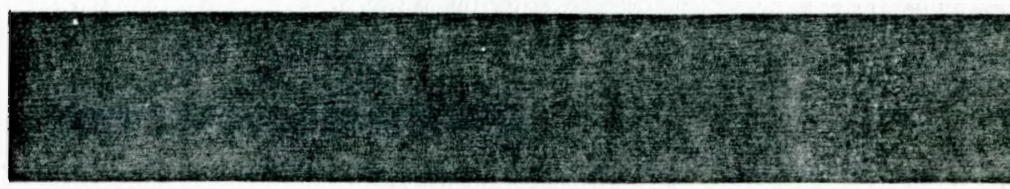

Liquid cadmium brightener for rack and barrel plating

\section{BENEFITS OF USING ENTHOBRITE CAD-904}

\section{Properties}

be Enthobrite CAD-904 process is alkaline.

an be used in both rack and barrel plating baths.

ompatible with most othe $r$ cadmium plating

righteners.

lsed in low concentrations.

mproves the covering and throwing power of the dating bath.

Mlghtener is consumed only during plating.

Inthobrite CAD-904 is a liquid cadmium rightener designed for addition to both rack and arrel plating baths to produce brilliant cadmium oposits at minimum cost.

The Enthobrite CAD-904 process produces uniform, mooth deposits over a wide range of current densies and improves both the covering and throwing ower of the cadmium plating solution. Cadmium eposits produced by the Enthobrite CAD-904 process re ideal for subsequent chromate conversion coatings.

For complete information on cadmium plating, cluding bath make-up, troubleshooting techniques, nd analytical control procedures, consult the Enthone alletin entitled "How to Cadmium Plate," which is vailable from your Enthone representative.

The Enthobrite CAD-904 process utilizes two quid materials: Enthobrite CAD-904M for make-up aly and Enthobrite CAD-904R for both make-up and plenishment. Enthobrite CAD-904M is available one quart ( 0.95 litre) containers; Enthobrite AD-904R is available in 5 gallon (19 litre) containers.

\section{Benefits}

No corrosive acid fumes.

Reduces the number of materials to be stocked and handled. Saves storage space.

Conversion of existing baths is simplified.

Economical to use.

Reduces both the plating time and the overall thickness of cadmium required to obta in adequate coverage of recessed areas.

No need to make additions of brightener after the bath has been idle for a few days.

HOW TO USE ENTHOBRITE CAD-904

\section{OPERATING CONDITIONS}

Concentration

Make-up

2 pints of Enthobrite CAD$904 \mathrm{M}$ and $3 \frac{1}{2}$ pints* of Enthobrite CAD-904R per 100 gallons of plating solution $(250 \mathrm{ml}$ of CAD $-904 \mathrm{M}$ and $437 \mathrm{ml}$ of CAD-904R per 100 litres)

Replenishment Under normal operating conditions, about one pint* of Enthobrite CAD-904R for each $25 \mathrm{lb}$. of sodium cyanide consumed during operation (1 litre/24 kg)

*Diluted 1:3 with water before adding. 


\section{APPENDIX VI}

ELECTROPLATING MASKING TAPE SPECIFICATIONS 
10. 470 ELECTROPLATING TAPE

JESCRIPTION: A yellow colored vinyl plastic tape with excellent resistance to most chemicals used in electroplating. Highly conformable, abrasion resistant.

ZONSTRUCTION:

Backing: Adhesive: Color:
Transparent vinyl plastic

Translucent, synthetic rubber Yellow

AVERAGE PHYSICAL PROPERTIES: (Fed. Std. 147) Not Recommended for Specification Purposes

Adhesion to Steel:

Tensile Strength:

Total Thickness:

Elongation at Break:
$45 \mathrm{oz} . /$ in. width $(49 \mathrm{~N} / 100 \mathrm{~mm})$

20 1bs./in. width $(350 \mathrm{~N} / 100 \mathrm{~mm})$

$7 \mathrm{mils}(.18 \mathrm{~mm})$

$225 \%$

GENERAL INFORMATION:

1. Excellent resistance to most chemicals used in electroplating operations.

2. Backing is highly conformable. Tape \#470 is used extensively for wrapping and patching coated racks, masking irregular surfaces and on compound curves.

3. Rugged backing offers necessary abrasion resistance to protect parts during rough handling.

4. Prolonged exposure to elevated temperatures (above $170^{\circ} \mathrm{F}\left[77^{\circ} \mathrm{C}\right]$ ) and hot caustics may cause weakening of adhesive bond.

5. Meets Federal Specification HH-T-0025 (GSA-FSS).

IMPORTANT NOTICE TO PURCHASER: Tapes identilied with a "Y" number are not standard, and, therefore, may be subject to modification, production limitations or cancellation by the manufacturer.

Al statements, technical information and recommendations contained herein are based on tests we believe to be reliable, but the accuracy or completeness thereof is not guaranteed, and the following is made in lieu of all warranties, express or implied: Seller's and manufacturer's only obligation shall be to replace such quantity of the product proved to be defective. Neither seller nor manulacturer shall be liable for any injury, loss or damage, direct or consequential, arising out of the use of or the inability to use the product. Belore using. user shall determine the suitability of the product for his intended use, and user assumes all risk and liability whatsoever in connection therewith. No statement or recommendation not contained herein shall have any force or effect unless in an agreement signed by officers of seller and manufacturer. 


\section{APPENDIX VII}

ELECTROPLAT ING CALCULATIONS 


\section{PLATING CALCULATIONS}

FERROVAC -E SAMPLE

Thickness

$0.20^{\prime \prime}$

Area (one side)
$1.0 \mathrm{in}^{2}=6.452 \mathrm{~cm}^{2}$
CADMIUM

Atomic No. $=\underline{48}$

Atomic Wt. $=112.41 \mathrm{gm}$ Mole

Density

$$
=8.65 \frac{\mathrm{gm}}{\mathrm{cm}^{3}}
$$

Valence $\quad=\underline{+2}$

USEFUL RELATIONSHIPS

1 Coul = 1 AMP-SEC (definition)

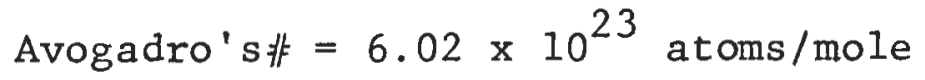

1 Electron (charge $=1.602 \times 10^{-19} \mathrm{coul}$

DESIRED PLATING THICKNESS - $0.0002^{\prime \prime}=0.000508 \mathrm{~cm}$

Volume of Plating $=\left(6.452 \mathrm{~cm}^{2}\right)(0.000508 \mathrm{~cm})=0.00328 \mathrm{~cm}^{3}$

WEIGHT OF PLATING $=\left(0.00328 \mathrm{~cm}^{3}\right)\left(8.65 \frac{\mathrm{gm}}{\mathrm{cm}^{3}}=0.0284 \mathrm{gm}\right.$

韭 OF MOLES $=0.0284 \mathrm{gm}$

$$
=2.522 \times 10^{-4} \text { Moles }
$$

\section{$112.41 \mathrm{gm} / \mathrm{Mole}$}

TOTAL CHARGE REQUIRED TO PLATE 0.0284 gm OF CADMIUM OUT OF THE CYANIDE BATH

$=\left(2.522 \times 10^{-4}\right.$ moles $)\left(6.023 \times 10^{23} \frac{\text { atoms }}{\text { moles }}\right)\left(\frac{\text { (2electrons })}{\text { atom }} \times\right.$

$$
\left(1.602 \times 10^{-19} \frac{\text { coul }}{\text { electron }}\right)
$$

$=48.68$ coul $=48.68 \mathrm{AMP}-\mathrm{SEC}$

USE ASF $=\frac{448.68 \mathrm{AMPS}-\mathrm{SEC}}{4 \mathrm{AMPS} / \mathrm{FT}^{2}}\left(\frac{144 \mathrm{IN}^{2}}{\mathrm{FT}}\right) / 1\left(\mathrm{IN}^{2}\right)=1752.5 \mathrm{SEC}$

PLATING CURRENT $=27.78 \mathrm{~mA}$ PLATING TIME $=29 \mathrm{MIN} 12.5 \mathrm{SEC}$ 


\section{B I BLIOGRAPHY}

Atrens, A. et al, "Electromechanical Studies of Hydrogen Diffusion and Permeability in Nickel," University of Notre Dame, 1979.

Bastien, P., and Azov, P., Proceedings of the First World Metals Congress, American Society of Metals, 1951. Beachem, C., Hydrogen Damage, American Society of Metals, 1977.

Bernstein, I., and Thompson, A., Hydrogen in Metals, American Society of Metals, 1974. Crank, J., The Mathematics of Diffusion, Clarendon Press, 1975.

Dage, E. et al, Proceedings of the Workshop on Alternatives for Cadmium Electroplating in Metal Finishing, Environmental Protection Agency, 1979.

Davis, H., and Gray, J., "Hydrogen Permeation Measurements on Some Electrodeposited Protective Coatings for High Strength Steels," Transactions of the Institute of Metal Finishing, Volume 46, 1968.

Devanathan, M., and Stachurski, Z., "The Adsorption and

Diffusion of Electrolytic Hydrogen in Palladium," Proceedings of the Royal Society, 1972.

Deville, H., and Troost, Compute Randes, 57, 1953 (referenced in Kuehler, C., Ph.D. Dissertation, Princeton University, 1974.) 
Federal Specification "QQ-P416C, P1ating, Cadmium

(Electrodeposited)," January 29, 1971.

Fontana, M., and Green, N., Corrosion Engineering, McGraw Hi11, 1971 .

Fischer, P., and Jankowski, J., "Determination of Hydrogen Generated by Paint Removers on Cadmium Plated Steel by the Electro-chemical Permeation Method," Naval Air Development Center, 1972.

Friberg, L., et al, Handbook of Toxicity of Metals,

Elsevier/North Holland Biomedical Press, 1980.

Guidebook and Directory, Metal Finishing, Metals and

Plastics Publishing Co., Inc., 1978.

Harris, I., and Farr, J., Hydrogen in Metals, Elsevier

Sequoia S. A., Lausanne, 1976.

Heidersbach, R. et al, "An Improved Electropermeation

Technique for Studying Hydrogen Transport in Metals," American Society of Metals, 1977.

Hoffner, "Solid Cadmium Embrittlement of 4340 Steel,"

Naval Air Development Center, 1974.

Jones, J. et al, "Hydrogen Permeation of High Strength Steels," Offshore Technology Conference Paper \#2801, 1977 .

Kerfoot, W., and Jacobs, S., Cadmium Accrued in Combined Wastewater Treatment-Aqua Culture Systems," Environmental Science and Technology, Vo1. 10, 1976. Latanison, R., et al, "Stress Corrosion Cracking and Hydrogen Embrittlement: Differences and Similarities," 
Massachusetts Institute of Technology, 1978. Mahan, B., University Chemistry, Addison Wesley Publishing Co., 1969.

Serota, L., "Cadmium Embrittlement," Metal Finishing, May, 1965 .

Surkein, M., Hydrogen Permeation in Iron at Low Temperatures,

M. S. Thesis, University of Rhode Island, 1979.

Thompson, A., and Bernstein, I., Effect of Hydrogen on

Behavior of Materials, The Metallurgical Society of AIME, 1976 .

Townsend, H., Jr., Hydrogen in Metals, American Society of Metals, 1973 .

Wanhill, R., and deRijk, P., "Hydrogen Embrittlement of 4340 Steel by Cadmium Electroplating; Interim Report \#1, "National Aerospace Laboratory NLR, The Netherlands, 1973. 